\title{
Género y edad en las necrópolis de la meseta norte durante la Edad del Hierro (siglos VI-II a. n. e.)
}

\author{
Gender and age in the Iron Age cemeteries of the North meseta $\left(6^{\text {th }}-2^{\text {nd }}\right.$ centuries BCE)
}

\author{
Raquel Liceras Garrido ${ }^{a}$
}

\section{RESUMEN}

Las necrópolis de la meseta constituyen uno de los conjuntos materiales fundamentales para entender la organización social de las comunidades del I milenio a. n. e. La tradición investigadora, que se remonta al siglo XVIII, frecuentemente ha atribuido algunos materiales de ajuar a un género o grupo de edad concreto sin el respaldo de análisis antropológicos. Desde la década de 1980, se han cuestionado dichas asociaciones y los estereotipos actualistas en que se basan. Este artículo se propone una aproximación inicial al tema de las relaciones entre los objetos funerarios y las características biológicas de los difuntos a partir de la bibliografía. Se centra en las necrópolis de Carratiermes, El Pradillo, Herrería III, La Yunta y Las Ruedas que cuentan con la información más completa. La muestra comprende 245 individuos para la Primera Edad del Hierro (siglos VI y IV a. n. e.) y otros 245 para la Segunda Edad del Hierro (finales del IV al II a. n. e.). Se analiza la distribución de la población por sexo y edad, atendiendo a la evolución de las curvas de mortalidad. También se lee la información en clave de género comparando las interpretaciones con los datos osteológicos. Además, se ofrecen algunas claves sobre la evolución de los materiales, la ausencia de marcadores de identidad y los principales ejes identitarios.

\begin{abstract}
The cemeteries of the meseta are essential to understanding the social organization of the communities of the $1^{\text {st }}$ millennium $B C E$. The research tradition, dating back to the $18^{\text {th }}$ century, has frequently attributed certain good graves to a gender or age group without the support of anthropological analyses. Since the 1980s such associations and the current stereotypes on which they based have come into question. Focusing on the cemeteries with greater information (Carratiermes, El Pradillo, Herrería III, La Yunta and Las Ruedas),
\end{abstract}

this article proposes a bibliographic approach to the relationships between funerary objects and the biological features of the deceased. The sample comprises 245 individuals for the Early Iron Age ( $6^{\text {th }}$ and $4^{\text {th }}$ centuries BCE) and another 245 for the Late Iron Age (late $4^{\text {th }}$ to $2^{\text {nd }} B C E$ ). The distribution of the population by sex and age is analyzed, considering the changes in the mortality curves. We also take gender into account by evaluating archaeological interpretations against the osteological data. Finally, the paper offers some keys on material culture changes, the absence of identity markers and the main axes of identitiy.

Palabras clave: necrópolis; meseta; Edad del Hierro; Celtiberia; Arqueología de género; Arqueología de la muerte; Arqueología del cuerpo; Arqueología de la identidad; infancia.

Key words: Cemeteries; meseta; Iron Age; Celtiberia; Gender Archaeology; Archaeology of death; Archaeology of the body; Archaeology of identity; childhood.

\section{INTRODUCCIÓN}

La investigación arqueológica del I milenio a. n. e. en la meseta norte apenas ha abordado estudios específicos relacionados con el reconocimiento y la caracterización del género o la edad en el pasado. Diversos factores han favorecido un discurso mayoritariamente androcéntrico, en el que los hombres jóvenes dedicados a actividades bélicas han sido los actores sociales más visibilizados desde la investigación. En algunos casos, las causas son de carácter arqueológico, como la escasa representación de la figura femenina en la iconografía de la región, las evidencias de construcciones defensivas prominentes y el protagonismo de las panoplias guerreras en los ajuares. En otros, se debe

a Digital Humanities Hub - History Department, Lancaster University. Department of History, FASS B005, Bowland College. Lancaster University LA1 4YW. Lancaster. United Kingdom. Correo e.: raquel.liceras@gmail.com; https://orcid.org/0000-0002-5552-9273

Recibido: 30-IX-2020; aceptado 1-II-2021. de uso y distribución "Creative Commons Reconocimiento 4.0 Internacional" (CC BY 4.0) 
a unos autores clásicos interesados en describir los enfrentamientos armados y el carácter beligerante de los locales durante la conquista de Hispania.

Las necrópolis de la meseta cuentan con una tradición investigadora de casi dos siglos de duración, desde los inicios de la Arqueología celtibérica, con la publicación de los resultados de las excavaciones en la necrópolis de Hijes por Francisco de Padua Nicolau Bofarull en 1850 (Lorrio 2005: 15), hasta las más recientes en Las Ruedas (Sanz Mínguez y Coria 2018). Las dos principales etapas de la investigación de estos conjuntos han sido el primer y último tercio del siglo $\mathrm{XX}$, por el elevado número de intervenciones, publicaciones e investigadores involucrados. A inicios de siglo, las excavaciones de Cerralbo, Cabré, Taracena o Morenas de Tejada en las cabeceras del Tajo, el Jalón y el Duero generaron un volumen material sin precedentes, aunque con limitadas posibilidades interpretativas. Las razones son las metodologías arqueológicas del momento que no pretendían definir registros detallados de contextos estratigráficos, dispersiones espaciales o asociaciones de materiales y el hecho de que la mayor parte de los trabajos quedaron inéditos, salvo los de Taracena. No obstante, contribuyeron a la construcción de secuencias crono-tipológicas ligadas a los contextos centroeuropeos (Dechelette 1913) y a las primeras obras de síntesis (Sandars 1913).

Tras un periodo de pausa durante la Guerra Civil y la Dictadura Franquista, las excavaciones en las necrópolis meseteñas se reanudaron en la década de 1970 con las intervenciones en Aguilar de Anguita (Argente 1976, 1977), Sigüenza (Cerdeño y Pérez de Ynestrosa 1993), Molina de Aragón (Cerdeño 1981, 1983), Carratiermes (Argente et al. 2001), Ucero (García Soto 1982) y La Dehesa de Ayllón (Barrio Martín 2006). En décadas posteriores, Teógenes Ortego publicó los materiales de una excavación de urgencia en La Revilla de Calatañazor y se revisaron conjuntos excavados en los años 30 como La Mercadera (Lorrio 1990). Al mismo tiempo, se comenzaron campañas en necrópolis como La Yunta (García Huerta y Antona 1992), El Pradillo (Moreda y Nuño 1990; Abarquero y Palomino 2007; Ruiz Vélez 2010), Aragoncillo (Arenas y Cortés 1997), Numancia (Jimeno et al. 2004), Herrería III (Cerdeño y Sagardoy 2007) o Las Ruedas en el área vaccea (Sanz Mínguez 1997) (Fig. 1).

\section{LA MESETA E IDENTIDADES DE GÉNERO Y EDAD: UN MARCO CONCEPTUAL}

Alberto Lorrio (2005: 111), ya desde la primera edición de Celtíberos, advertía del enfoque meramente tipológico generalizado en el estudio de las necrópolis de la Celtiberia, centrado sobre todo en armas, fíbulas o placas de cinturón. Esto se debe fundamentalmente a la pervivencia del paradigma histórico-cultural de finales del siglo XX que ha ocasionado un triple efecto en la investigación: el protagonismo de la tipología y la seriación de armas, fíbulas o placas de cinturón metálicas; la identificación geográfica y espacial de las etnias citadas por los autores grecorromanos; y el interés por los aspectos cosmogónicos y rituales. Esos precedentes han permitido construir sólidas secuencias de materiales (e. g. broches de cinturón, fíbulas, armas, etc.) y un registro cultural extenso que nos da la oportunidad de ir más allá de los tipos y periodización de los materiales. Sin embargo, se han explorado escasamente sus posibilidades sobre cuestiones de identidad en general, y de género en particular, contribuyendo, en ocasiones, a perpetuar asociaciones engañosas de artefactos rebatidas hace décadas.

Las Arqueologías de género y feminista surgidas hace más de 30 años han criticado el foco androcéntrico en la interpretación arqueológica (e. g. Conkey y Spector 1984; Arnold 1991; Querol y Triviño 2004; Montón Subías y Lozano Rubio 2012; Díaz Andreu y Montón Subías 2013), evidenciando cómo las mujeres durante la Prehistoria, o bien no están representadas en las narrativas arqueológicas, o bien se identifican con dos estereotipos principales: iconos altamente sexualizados como las "venus" prehistóricas o madres reproductoras y cuidadoras de sus criaturas (Alarcón y Sánchez Romero 2015: 50). Este hecho ha servido para perpetuar la idea de que la mujer es un ser social secundario sin capacidad de acción, quien carece de un papel relevante en la configuración y dinámicas de las sociedades del pasado. Sin embargo, estas arqueologías también ofrecen una batería de herramientas teóricas y metodológicas que permiten rebatir esos paradigmas y realizar lecturas de género del pasado (e. g. Gero y Conkey 1991; Sørensen 2000; Arnold y Wicker 2001; Hernando 2002; Sánchez Romero 2005a, 2007; Cruz Berrocal 2009; Sofaer y Sørensen 2013; Sánchez Romero y Cid López 2018).

Los conceptos de identidad e interseccionalidad han sido esenciales para abordar las construcciones de género en el pasado. Las identidades son mecanismos por los que el individuo se autoidentifica con un colectivo más amplio (Hernando 2002: 16, 2012: 31; Díaz Andreu 2005). Estas son múltiples, mutuamente construidas y están entretejidas y en constante interacción e interrelación. El género o la edad, ejes vertebradores de la esencia del individuo, influyen en como la persona se conceptualiza a sí misma y es percibida por los demás. Al estar dichas identidades íntimamente ligadas y en permanente intersección, se modifican inexorablemente la una a la otra con el paso del tiempo, las experiencias vitales u otros ejes identitarios como el estatus, la clase, la familia o la etnicidad, repercutiendo en la

Trab. Prehist., 78, N. ${ }^{\circ}$ 1, enero-junio 2021, pp. 121-139, ISSN: 0082-5638

https://doi.org/10.3989/tp.2021.12268 


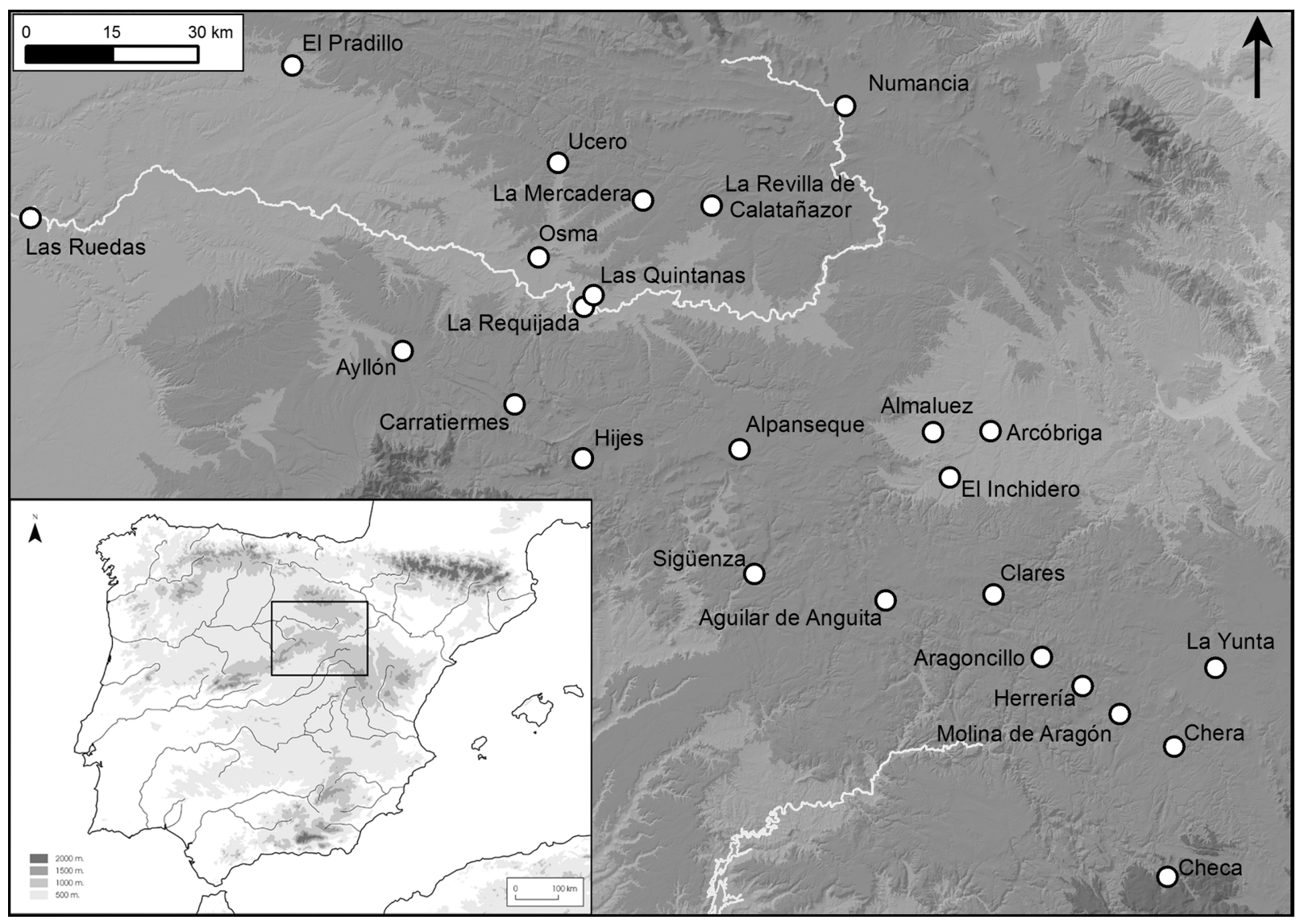

Fig. 1. Distribución espacial en la península ibérica de las necrópolis de incineración del I milenio a. n. e. de la meseta norte mencionadas en este artículo sobre el MDE de 50 m/px del Instituto Geográfico Nacional.

posición social que la persona ocupa en la comunidad (Fig. 2).

Al mismo tiempo, las identidades en intersección para ser efectivas han de ser practicadas, actuadas y materializadas a través del cuerpo. La cultura material generada a lo largo de la vida del sujeto está en permanente construcción, reconstrucción y destrucción. Las fluctuaciones en las relaciones y el desarrollo de las biografías de las personas y los objetos transforman los significantes y significados. Además, en el estudio de los contextos funerarios, contamos con los significantes que una persona portaba en su día a día, y también con la capacidad de acción y las narrativas que familiares u otros miembros de la comunidad involucrados en los rituales quisieron exhibir o enfatizar.

Desde los orígenes de la arqueología en la meseta norte, ha habido algún intento por tratar de entender la estructuración de las sociedades del I milenio a. n. e. en términos de género y edad. Así lo demuestran las propuestas de clasificación de las tumbas excavadas por Ricardo Morenas de Tejada (1916a: 173, 1916b: 607, citado en Lorrio 2005: 140-144) en La Requijada y Osma, como pertenecientes a hombres guerreros, ornamentadas mujeres y niños. Las interpretaciones, sin embargo, resultaron sesgadas por la falta de recogida sistemática de los restos óseos de las cremaciones, la escasa cantidad en algunas ocasiones de material bioantropológico analizable, la ausencia de análisis antropológicos y los complicados códigos simbólicos que encerraban los ajuares, reproduciendo tanto los cánones mediterráneos transmitidos por los mitos clásicos (ampliado en García Huerta 2013-2014) como los actualismos propios de la época de los investigadores.

Desde la década de los 70, gracias a la introducción progresiva de los análisis osteológicos de los restos de cremación de las necrópolis -incluyendo las analíticas de isótopos y los estudios de ADN en otras regiones-, las asociaciones de género, edad y ciertos materiales arqueológicos se han podido abordar desde perspectivas más amplias. Esto ha permitido repensar los cánones interpretativos forjados a inicios del siglo XX con 


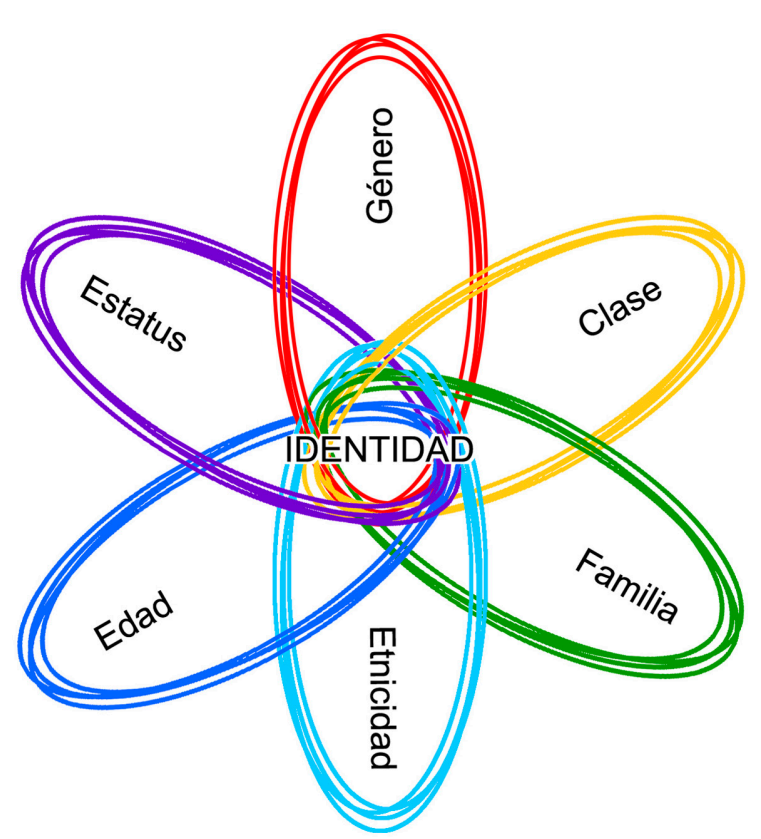

Fig. 2. Interseccionalidad en las identidades esenciales para abordar las construcciones de género en el pasado. En color en la edición electrónica.

los datos físicos y biológicos de los individuos depositados en los cementerios, de modo que ahora se asume que el reconocimiento social de las diferencias sexuales entre individuos y su materialización en prácticas funerarias no pueden darse por sentadas. Las identidades de género ya no se entienden como meros hechos biológicos innatos, sino como parte de un proceso de construcción ideológica e identitaria colectivas (Belar 2017). La Dama de Baza o la tumba de la "princesa" de Vix son casos paradigmáticos de como ciertos valores de género o papeles sociales trascienden el sexo (Arnold 1991, 2016; Quesada 2010: 163-165; Prados 2011: 208). Asimismo, objetos como las armas, los pectorales, los broches de cinturón, los soportes "de tocado" o las fusayolas podrían estar reflejando tanto aspectos de la personalidad del individuo enterrado como las intencionalidades de sus allegados.

La Arqueología de género posibilita así una aproximación crítica a paradigmas tradicionalmente aceptados desde una óptica social contemporánea y occidental. Sin embargo, su impacto en algunas regiones de la península ibérica como la meseta norte ha sido muy reducido. Tan solo destacan algunas interpretaciones en esta línea sobre tumbas muy concretas de los enterramientos femeninos e infantiles de Las Ruedas (Sanz Mínguez y Romero 2010; Sanz Mínguez y Diezhandino 2007; Sanz Mínguez 2015; Sanz Mínguez y Coria 2018) u objetos particulares como las fusayolas (Gar- cía Huerta 2013-2014) o los conocidos como "soportes para tocado" (Chordá y Pérez Dios 2014). Sin embargo, esta región carece de síntesis en clave de género, a pesar de que las necrópolis excavadas desde finales de los 70 cuentan con análisis osteológicos de los restos humanos de los enterramientos.

Este es un artículo inicial sobre el significado social de la construcción de las identidades durante la Edad del Hierro a partir de las prácticas sociales y la cultura material, recurriendo a los objetos de los ajuares y a los resultados de los análisis osteológicos efectuados en las últimas décadas. El estudio tendrá en cuenta toda la información disponible en la meseta norte, pero se centrará en las cinco necrópolis con los datos arqueológicos y osteológicos más completos publicados: Carratiermes, El Pradillo, Las Ruedas, La Yunta y Herrería III. Dado que se trata de una primera aportación su base es principalmente bibliográfica. Sin duda, una revisión en profundidad de los fondos museográficos y un análisis global de todo el registro material, incluyendo nuevas analíticas, enriquecerían sustancialmente la visión del tema.

\section{DISTRIBUCIÓN DE POBLACIÓN EN LAS NECRÓPOLIS: SEXO Y EDAD}

Morenas de Tejada (1916a: 173, 1916b: 608), en sus lecturas tradicionales del contenido de los ajuares de Gormaz u Osma, señalaba que la mayor parte de los individuos allí depositados eran varones, mientras las mujeres y los niños eran una minoría. Este trabajo busca contrastar esa afirmación y observar los patrones de sexo y edad, estudiando la distribución de la población a partir de las cinco necrópolis de la meseta norte con los datos más amplios sobre las características biológicas de los individuos y la atribución cronológica de sus ajuares.

Más de un centenar de cementerios y decenas de miles de enterramientos se han excavado en esta región, pero los conjuntos documentados arqueológicamente y publicados son muy pocos. En este trabajo, se han excluido de los cálculos los cementerios con datos de menos de 5 individuos, poco diagnósticos a la hora de extraer conclusiones estadísticas generales, como es el caso de El Pradillo durante la Segunda Edad del Hierro para la que tan solo se analizaron los datos de 3 cremaciones de esta fase (Ruiz Vélez 2010: 151) o Numancia en la que se identificaron solo 2 individuos sin edad determinada, ya que la media de restos óseos por tumba era $5,73 \mathrm{~g}$, insuficiente para determinar sexo y edad en la mayoría de los enterramientos (Jimeno et al. 2004: 439).

El total de 490 individuos considerados en este trabajo proceden de La Yunta (Reverte en García Huerta 
y Antona 1992: 23-106), Las Ruedas (Reverte en Sanz Mínguez 1997: 532-541), Carratiermes (Reverte en Argente et al. 2001: 234-239, 300-304), Herrería III (Gómez Bellard en Cerdeño y Sagardoy 2007: 149-151, 187-197) y El Pradillo (Reverte en Ruiz Vélez 2010: 151). La muestra se ha dividido en dos grupos cronológicos: 245 individuos corresponden a la Primera Edad del Hierro (siglos VI y IV a. n. e.) y otros 245 a la Segunda Edad del Hierro (finales del IV al II a. n. e.).

Como se observa en la tabla 1 la distribución de los datos por sexo es similar en todas las necrópolis, incluyendo Carratiermes cuya muestra es la más amplia en ambos periodos. A la luz de estos datos, las afirmaciones sobre el predominio de varones en los cementerios carecen de fundamento.

\begin{tabular}{|l|c|c|c|c|}
\hline Necrópolis & $\begin{array}{c}\text { Infan- } \\
\text { tiles }\end{array}$ & Mujeres & Varones & $\begin{array}{c}\mathbf{N}^{\mathbf{0}} \text { de } \\
\text { individ. }\end{array}$ \\
\hline \multicolumn{5}{|c|}{ Primera Edad del Hierro } \\
\hline Carratiermes & 24 & 77 & 61 & 162 \\
\hline El Pradillo & 5 & 14 & 10 & 29 \\
\hline Herrería III & 9 & 10 & 10 & 29 \\
\hline Las Ruedas & 7 & 13 & 5 & 25 \\
\hline Total & 45 & 114 & 86 & 245 \\
\hline \multicolumn{5}{|c|}{ Segunda Edad del Hierro } \\
\hline Carratiermes & 29 & 62 & 66 & 157 \\
\hline La Yunta & 5 & 27 & 30 & 62 \\
\hline Las Ruedas & 1 & 10 & 15 & 26 \\
\hline Total & 35 & 99 & 111 & 245 \\
\hline
\end{tabular}

Tab. 1. Distribución de individuos por necrópolis, sexo y cronología en las estudiadas de la meseta norte.

Los datos se han desglosado por criterios de sexo y grupo de edad a partir de los números totales por necrópolis y periodo. Los sujetos adultos con información sobre sexo han sido incluidos en las categorías biológicas identificadas por los antropólogos: varones y mujeres. Los individuos infantiles sin posible determinación de sexo han sido agrupados como infantiles. Al mismo tiempo, el informe osteológico de Herrería III desglosa tres grupos de edad: infantiles, jóvenes y adultos, mientras los informes de los restantes cementerios permiten la agrupación convencional de los adultos en rangos de edad por décadas. Los infantiles han sido desagregados en las categorías de nonatos, 0-1 año, 1-5, 5-10 y 10-15 años que permiten una mayor flexibilidad a la hora de interpretar las curvas de mortalidad (Fig. 3).

En los dos periodos de uso de las necrópolis, se observa como los varones presentan edades comprendi- das entre los 20 y los 70 años, llegando a documentarse un varón que pudo haber alcanzado los 80 años en la necrópolis de Carratiermes (tumba 605). No aparece en la figura, ya que su ajuar no permitió una asignación cronológica concreta. También se identifican mujeres con edades entre los 12 (Carratiermes, tumba 237) y los 70 años. Se pueden advertir patrones comunes de mortalidad entre hombres y mujeres, aunque se aprecian diferencias entre necrópolis (Fig. 4).

La tendencia y la tasa de mortalidad son muy similares en ambos periodos de la Edad del Hierro. Los rangos de edad en los que están presentes mujeres y hombres son prácticamente iguales y se advierten dos picos de mortalidad fundamentales: durante la infancia entre los 0-5 años de vida y entre los 30-40 años.

El primero de los picos de mortandad coincide con uno de los colectivos más invisibilizados ante la muerte, la infancia. La mortalidad en el momento del parto y en los primeros años de vida debió suponer un riesgo significativo como se observa en la curva ascendente desde el nacimiento hasta los 5 años de edad. Una vez superada esa barrera, la curva de mortandad sufre un paulatino descenso hasta alcanzar la edad adulta. Los/as niños/as han sido documentados en tumbas individuales y múltiples. La asociación más común es la de mujer y un infantil, aunque también se registran enterramientos de dos individuos menores (Carratiermes, tumba 573); un infantil y un hombre (Carratiermes, tumba 282; Las Ruedas, tumba 8); un varón, una mujer y un infantil (El Inchidero, tumba C5T9) o varios infantiles y un adulto (El Inchidero, tumba C3T12).

En las necrópolis meseteñas, los infantiles suponen el $16 \%$ y el $14 \%$ de los individuos enterrados para la Primera y Segunda Edad del Hierro, respectivamente. Datos similares recoge Isabel Izquierdo (2007) para el área ibérica, recopilando los resultados de necrópolis como Pozo Moro (23,2 \% de los individuos depositados), Los Villares de Hoya Gonzalo (10\% del total), Cabezo Lucero $(9,5 \%$ ) o el Puntal de Salinas o el Corral de Saus, donde correspondían a un $13 \%$ en cada caso.

La escasa representatividad de la infancia en los estudios funerarios combina la falta de un interés específico sobre el tema con la dificultad material de su identificación (Chapa 2003), ya que no parecen existir unos marcadores materiales concretos. A esto se une la existencia de un segundo ritual de enterramiento por inhumación bajo los suelos de las casas. Estos se conocen en enclaves de poblamiento coetáneos como El Castillejo de Fuensaúco (Romero y Misiego 1995) o La Coronilla de Chera (Cerdeño y García Huerta 1992). A pesar del debate existente sobre por qué en algunos casos los infantiles eran inhumanos o cremados, o las diferencias rituales entre depositarlos junto a los hogares de la vi- 


\section{Primera Edad del Hierro}

Herrería III

\section{El Pradillo}

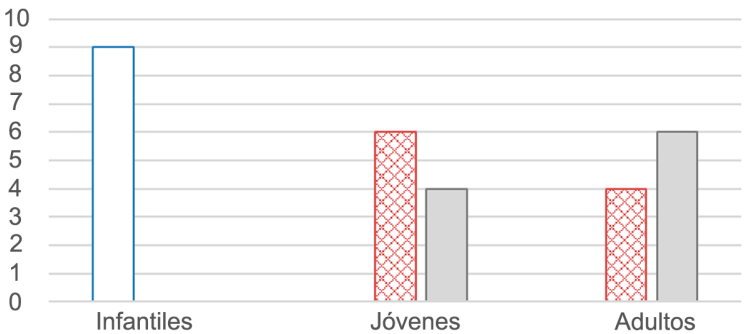

Carratiermes

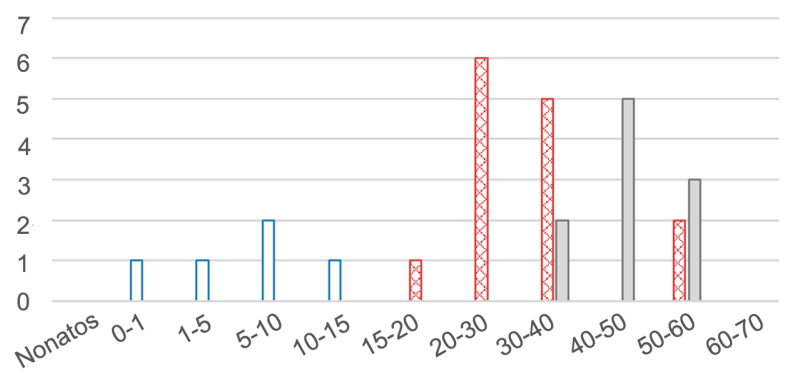

Las Ruedas. Fase I-II
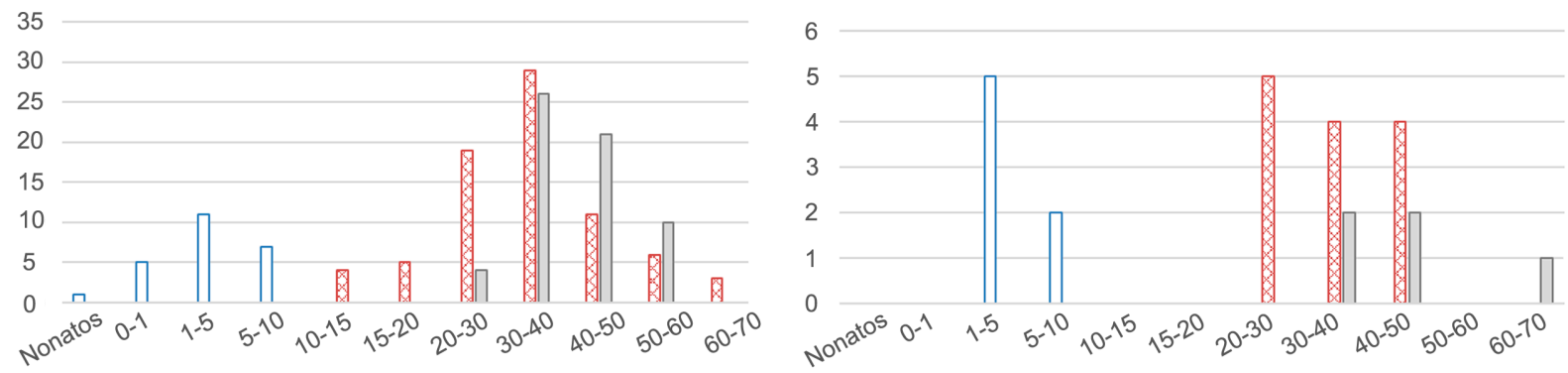

\section{Segunda Edad del Hierro}

\section{Carratiermes}

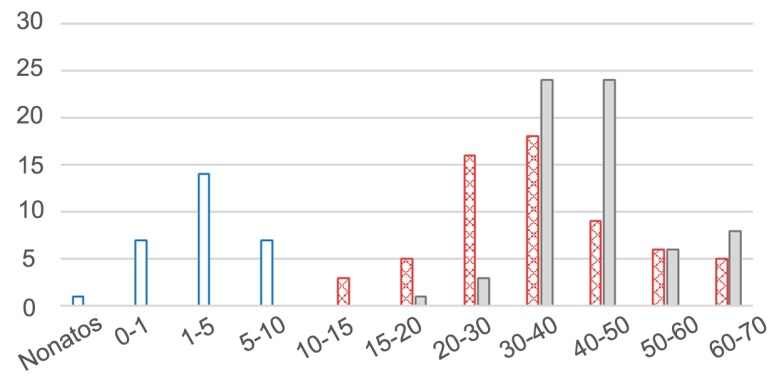

Las Ruedas. Fase III-IV

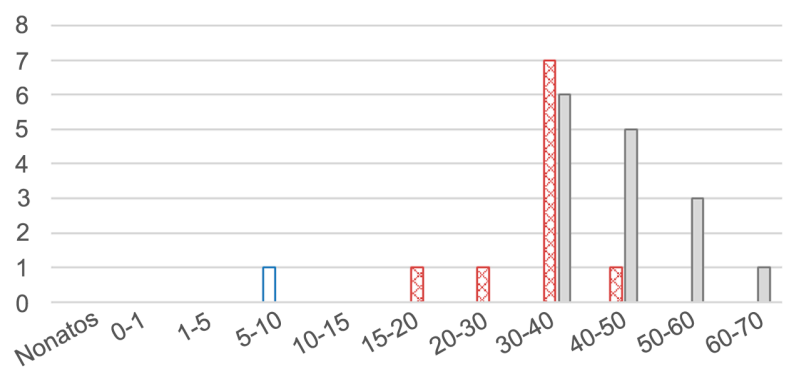

La Yunta

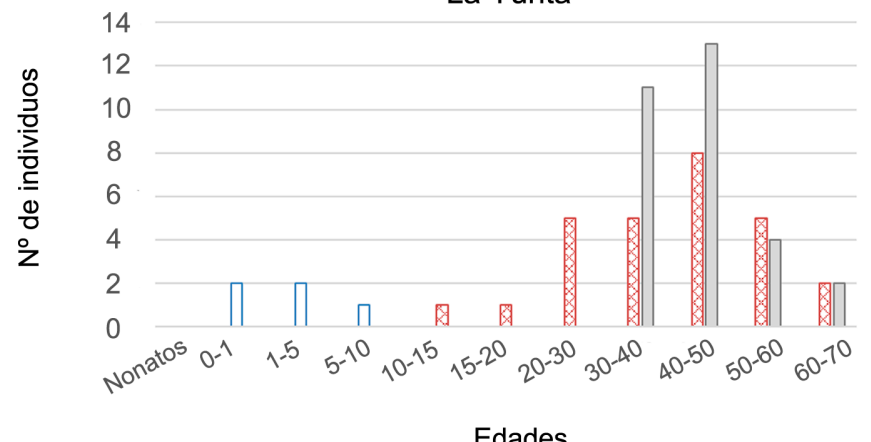

\section{Edades}

Fig. 3. Número de individuos identificados por sexo y edad en las necrópolis de incineración de la meseta norte. En color en la edición electrónica. 
vienda familiar o en el cementerio comunitario cremados o inhumados (e.g. Herrería III, tumba 51) (Gusi y Muriel 2008; Sánchez Romero 2010; Sánchez Romero et al. 2015; Moreno Ojeda 2019). Los interrogantes aún son numerosos por el limitado conjunto de datos y la variabilidad regional de las prácticas funerarias.

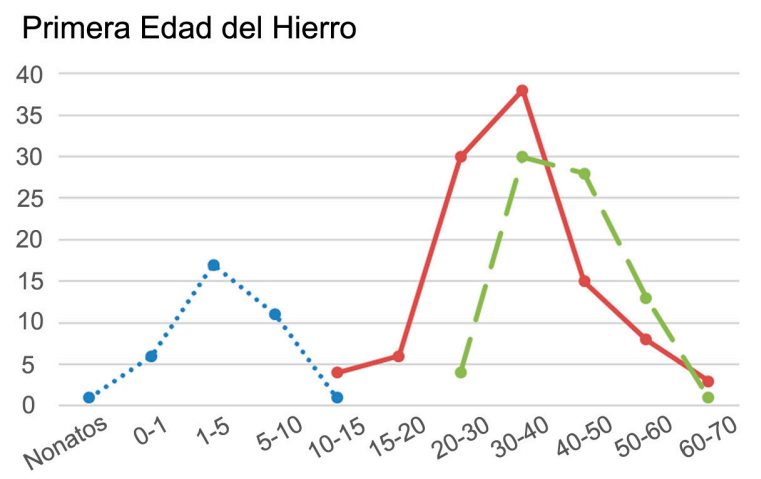

\section{Segunda Edad del Hierro}

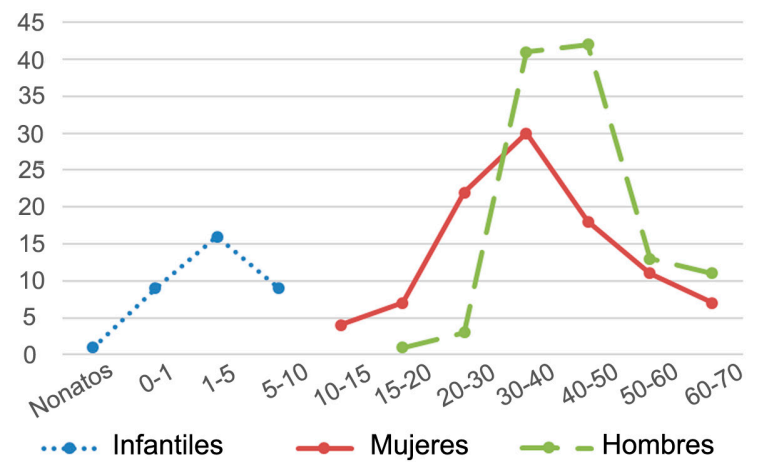

Fig. 4. Curvas de mortalidad en las necrópolis de incineración de la meseta norte desagregadas por sexo y edad. En color en la edición electrónica.

El segundo de los picos de mortalidad corresponde al rango de edad donde se sitúa la estimación de la esperanza de vida en ambos periodos y sexos. La vida media de un hombre eran los 36 años en la Primera Edad del Hierro y la de las mujeres los 29. Estas cifras aumentan ligeramente durante la Segunda Edad del Hierro: hasta 38 años los hombres y 32 las mujeres. Estos datos son similares a los documentados en el área ibérica, donde el promedio de edad de los varones eran los 30-40 años y el de las mujeres los 20-30 años (Izquierdo 2007).

El desequilibrio en los años de esperanza de vida entre hombres y mujeres podría estar muy influido por dos elementos principales. El incremento sustancial a partir de los 20 años en la mortalidad de las mujeres puede relacionarse con los peligros relacionados con la gestación, la maternidad y la lactancia (Sánchez Rome- ro 2006). En segundo lugar, en las necrópolis de la meseta, los hombres enterrados menores de 30 años son tan solo 8 de un total de 490 individuos. Este hecho podría asociarse con su defunción durante actividades realizadas a larga distancia de los enclaves de población como podrían ser el comercio o el mercenariado. Ligado a la actividad bélica y mercenaria, se encuentra también el rito funerario de la exposición de cadáveres, reservado a los guerreros caídos en batalla, que podemos suponer afectaría mayormente a este grupo de edad entre los hombres.

El número de individuos que superaban los 50 años era muy reducido, lo que puede asociarse a la baja esperanza de vida. En los análisis antropológicos, se detectaron algunas patologías que afectaban a sujetos de ambos sexos en edades avanzadas como la artrosis (tumbas 3 y 27 de Las Ruedas), la osteoporosis (tumbas 42 y 73 de El Pradillo), pérdidas dentarias o piorrea y la abrasión dental relacionada con una dieta alimenticia dominada por el componente vegetal (Sanz Mínguez 1997: 496, 533; Ruiz Vélez 2010: 154).

\section{TEJIENDO IDENTIDADES: OBJETOS DE AJUAR Y PRÁCTICAS SOCIALES}

Además de las características biológicas analizadas en el apartado anterior, las prácticas sociales y la cultura material depositada en los ajuares son dos elementos clave para descifrar cómo se construyeron, manifestaron o negociaron identidades como el género, la edad, el estatus social o la etnicidad en las sociedades del I milenio.

Al tratar la dimensión funeraria, los ajuares han sido uno de los factores determinantes para entender las dinámicas y transformaciones sociales de las comunidades del pasado. Los elementos que más han influido en la categorización de los ajuares son tres. El primero es el concepto de riqueza. Esta ha sido asociada a la abundancia de materiales y a su exotismo, al tiempo que los materiales depositados como ajuar eran entendidos como la riqueza real de la persona allí enterrada. Sin embargo, las pertenencias del difunto o difunta podrían haber pasado a sus allegados o herederos, por lo que los elementos que registramos en los ajuares son el testimonio o nivel de "riqueza" que los vivos, actores principales de los rituales funerarios, quisieron atribuir al fallecido (Parker Pearson 1993; Cerdeño y García Huerta 2001; Prados 2011-2012; Belar 2017).

El segundo elemento son los ajuares-tipo engañosos asociados a identidades de género como, p. ej., armas $=$ hombres, ornamentos $=$ mujeres o elementos textiles $=$ mujeres.

Por último, el armamento ha influido los ajuarestipo desde los primeros trabajos. Recordemos las afirmaciones de Ricardo Morenas de Tejada citadas 
con anterioridad o las interpretaciones de Juan Cabré (1916-1917: lám. XLV) sobre los enterramientos de guerreros y sus esposas inmoladas a su muerte (tumba 11 de Gormaz). Esta preeminencia de las armas podría atribuirse a dos motivos fundamentales. Además de abundantes en número, son ricas en tipos, formas y decoraciones en la mayor parte de las necrópolis meseteñas excavadas a inicios del siglo XX. Por eso, su presencia/ausencia supuso un significativo sustento para los primeros intentos de clasificación de materiales que han servido como soporte de las tipologías actuales. En segundo lugar, la prominencia de las armas en los discursos arqueológicos de investigación habría estado relacionada con una mayoría masculina en los investigadores que desde los inicios de la arqueología profesional erigieron los cimientos interpretativos de la disciplina, con la excepción de figuras singulares como Encarnación Cabré. Esto favoreció el estudio de la cultura material desde perspectivas en las que el género masculino se veía reflejado como la guerra, la caza o el trabajo de los metales, desplazando a un segundo plano actividades llevadas a cabo por mujeres como las textiles o de mantenimiento (Sánchez Romero 2005b; Hernando 2012; Orozco-Köhler 2016).

\subsection{La relevancia de las armas}

La asociación de las armas a una actividad guerrera llevada a cabo por hombres ha estado ligada a múltiples referencias de autores clásicos como Polibio (XVI, 7,5), Justino (Ep. XLIV, II), Floro (1, 34, 3-4), Livio $(34,17)$, Trogo Pompeyo $(44,2,3)$ o Diodoro $(33,25)$, entre otros. Estos remarcaron el gran espíritu guerrero de los pueblos meseteños, imbatibles en los combates, quienes amaban más a sus armas que a sus vidas, llegando a considerar su pérdida en la batalla como la pérdida de sus propias manos. Sin embargo, en las necrópolis de la meseta, las armas aparecen depositadas en tumbas independientemente del sexo o la edad de los individuos allí enterrados. Según la necrópolis, varía el número de enterramientos en los que se registran: desde el $44 \%$ en La Mercadera hasta su ausencia en El Pradillo (Tab. 2).

Lo más frecuente en los ajuares con armas entre los siglos VI y IV a. n. e. es combinar más de un ejemplar por tumba. Los tipos mayoritarios son las lanzas (puntas y regatones), los cuchillos curvos y, a veces, espadas, escudos o arreos de caballo. Junto a las armas, se documentan equipos de aseo personal, vasijas cerámicas, canicas, fusayolas u ornamentos como fíbulas. A partir del siglo III a. n. e., de la mano de los cambios sociales derivados del mundo urbano, la preponderancia de las armas se redujo en algunas de las necrópolis, sus tipos cambiaron y su decoración aumentó. En
Carratiermes, las lanzas disminuyen en favor de los puñales ornamentados, observándose una tendencia similar en Las Ruedas. Complicadas decoraciones comenzaron a aparecer en lanzas, vainas y empuñaduras de puñales y espadas, siendo quizá los tipos de antenas atrofiadas y Arcóbriga los más ornamentados. Además, surgen elementos defensivos con más vocación de exhibición de poder y prestigio que una utilidad práctica en el combate como los cascos de bronce (tumba 39 de Numancia, Aguilar de Anguita, Alpanseque, Almaluez o los depósitos de La Fuentona y Aranda de Moncayo) o los cardio-torax (Graells 2012).

\begin{tabular}{|c|c|c|}
\hline Necrópolis & Tumbas totales & $\begin{array}{c}\% \text { de ajuares con } \\
\text { armas }\end{array}$ \\
\hline \multicolumn{3}{|c|}{ Primera Edad del Hierro } \\
\hline Carratiermes & 199 & $13,5 \%$ \\
\hline El Pradillo & 29 & $0 \%$ \\
\hline Herrería III & 153 & $22 \%$ \\
\hline Las Ruedas & 27 & $37 \%$ \\
\hline \multicolumn{3}{|c|}{ Segunda Edad del Hierro } \\
\hline Carratiermes & 235 & $35,7 \%$ \\
\hline La Yunta & 112 & $11,9 \%$ \\
\hline Las Ruedas & 35 & $34 \%$ \\
\hline
\end{tabular}

Tab. 2. Porcentaje de ajuares con armas por periodo en las necrópolis de la meseta norte (datos a partir de García Huerta y Antona 1992; Sanz Mínguez 1997; Argente et al. 2001; Lorrio 2005: 135-141; Cerdeño y Sagardoy 2007: 134-135).

Tal y como se afirmaba antes, las armas fueron depositadas junto a individuos de todas las edades y de ambos sexos, desde tumbas dobles con un feto y una mujer hasta individuos de 70 años (Fig. 5). La relación de infantiles con ajuares con armas se aprecia más intensamente en la necrópolis de Carratiermes, el cementerio con mayor número de menores documentados, aunque la misma tendencia puede advertirse en el resto de cementerios. La distribución de armas en ajuares femeninos y masculinos parece equilibrada en términos generales, aunque se observan diferencias entre necrópolis y periodos. La mayoría de las mujeres enterradas con armas se concentran en el tramo de edad de los 20-30 años, mientras se aglutinan en torno a los 30-50 años en los varones, unas y otros coinciden con los periodos de mayor mortalidad de la etapa adulta.

Como viene defendiendo este trabajo, los objetos de los ajuares son polisémicos y sus significados no les son inherentes sino que dependen del contexto en el que fueron depositados. Por ello, dentro del simbolismo social y de prestigio que objetos como las armas representarían, han de ser entendidos los ajuares con es- 

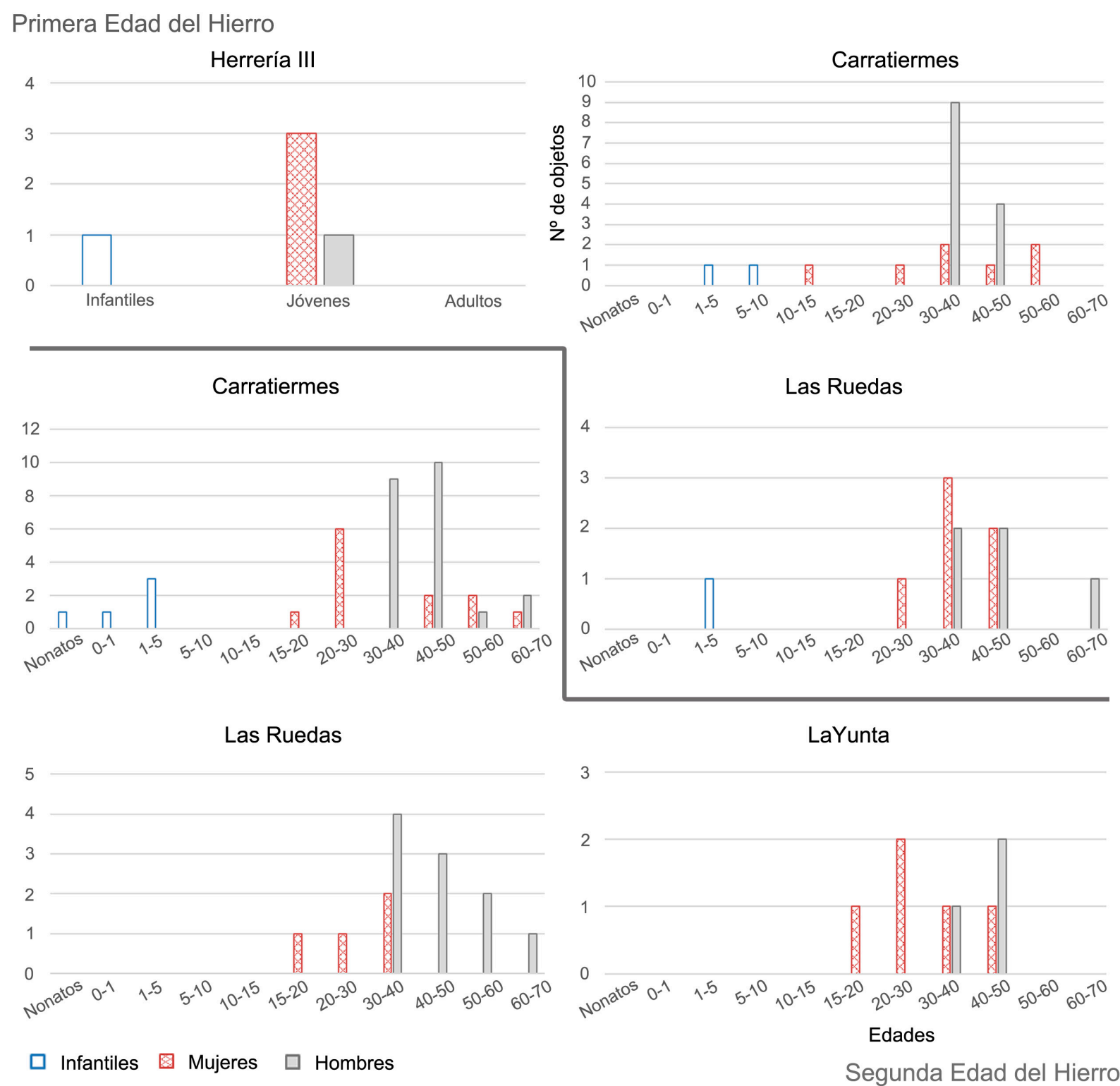

Las Ruedas

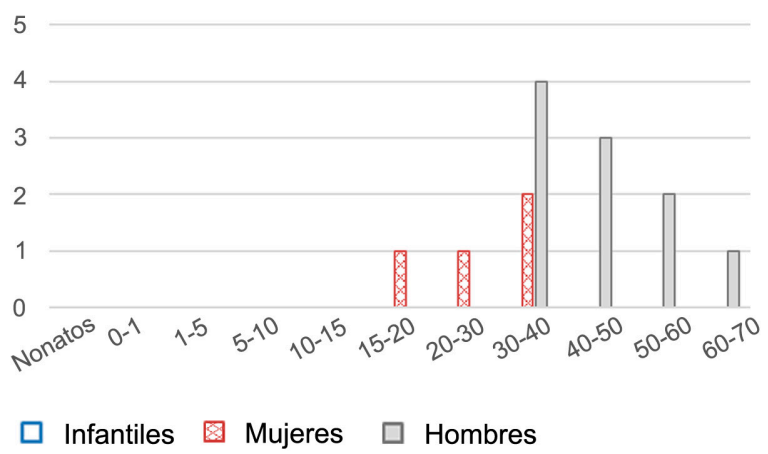

Fig. 5. Datos de los ajuares con armas en las necrópolis de incineración de la meseta norte a partir de los datos osteológicos.

padas como los de Herrería III (tumba 51: mujer joven e infantil inhumado; tumba 27: mujer joven) (Cerdeño y Sagardoy 2007), o con panoplias guerreras completas y arreos de caballo tan prototípicos en Carratiermes (e. g. tumbas 302 y 347: mujeres de 50-60 años; tumba 262: infantil) (Argente et al. 2001) o Sigüenza (tumba 1: mujer de 20-30 años) (Cerdeño y Pérez de Ynestrosa 1993) (Fig. 6). No obstante, cabe destacar al grupo de varones adultos que están enterrados con armas (en general dos lanzas, regatón o regatones y cuchillos curvos), arreos de caballo, objetos de aseo personal y algún elemento de adorno como fíbulas, cuyos ajuares podrían estar marcando su vinculación con un tipo de identidad de clase correspondiente a los guerreros.

\subsection{Los equipos de aseo personal y la clase guerrera}

La clase es una forma de identidad relacional por la que un individuo se vincula emocionalmente a un grupo sobre el que asienta su sentido de pertenencia. 


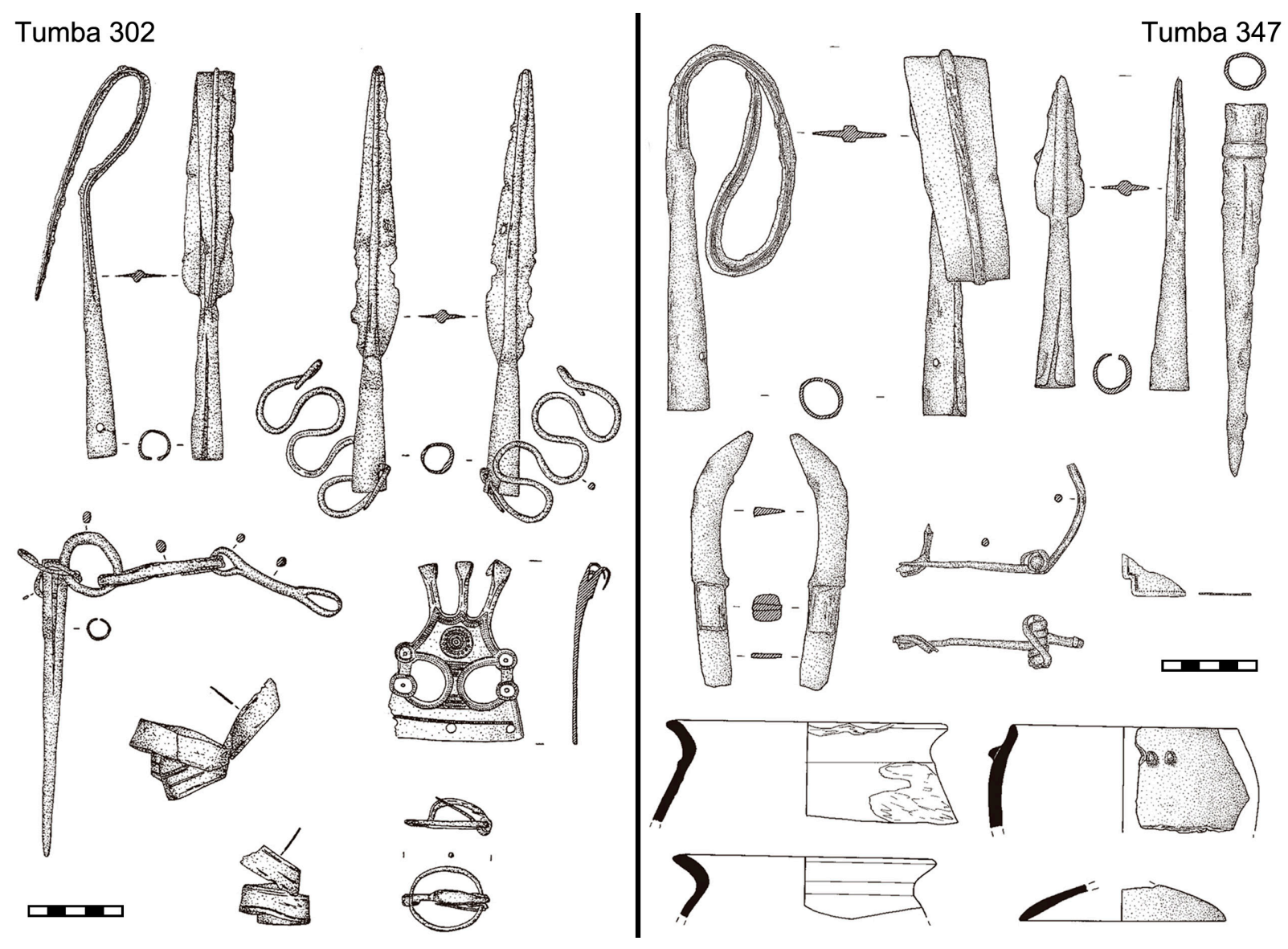

Fig. 6. Enterramientos de mujeres (50-60 años) de las Tumbas 302 y 347 de Carratiermes con armas en sus ajuares (a partir de Argente et al. 2001: cd, tumba 302 y 347).

A. Hernando (2012: 68) la caracterizaba como: "grupos humanos que se perciben a sí mismos a través de esta identidad relacional visibilizan esta adscripción a través de la expresión unificada de su apariencia: todos los miembros del grupo visten igual, o se adornan igual o utilizan algún elemento distintivo que los diferencia como grupo". Al mismo tiempo que sus integrantes desarrollan estas prácticas corporativas de identificación, crean una serie de mecanismos segregacionistas que les permite aislarse del grupo ${ }^{1}$. De este modo, mediante la reiteración visual a través del cuerpo, al vestir o portar determinados objetos, además de la gestualidad que esto conllevaría, se definen como sujetos sociales y se determina su lugar en la comunidad. Desde esta perspectiva, esta clase guerrera aglutinaría a integrantes del género masculino que se podían permitir portar armas,

${ }^{1}$ L. Moragón. Cuerpo y sociedades orales. Una reflexión sobre la concepción del cuerpo y sus implicaciones en el estudio de la Prehistoria. Tesis Doctoral inédita, Universidad Complutense, 2013, p. 229. lucir una apariencia determinada y poseer un caballo (Fig. 7A). Sin embargo, a pesar de la fuerte estandarización de este grupo, se aprecian sutiles diferencias de riqueza entre sus integrantes, marcadas por el número de armas, su variedad, decoración y procedencia.

Es frecuente documentar la existencia de enterramientos con ajuares con armas, pero sin restos de la cremación del difunto; por ejemplo, en Carratiermes para la Segunda Edad del Hierro el 27,3 \% de los ajuares con armas no tenían restos humanos. Esto podría relacionarse con la posibilidad de que dichas tumbas correspondiesen a individuos fallecidos en otros lugares (García Huerta 2013-2014: 301) a los que se les dedica un enterramiento simbólico en su ciudad de origen o residencia. Posiblemente, algunos de esos individuos podrían haber pertenecido a la clase de los guerreros que viajaban por toda la península ibérica y el Mediterráneo recogiendo influencias culturales que posteriormente quedaron reflejadas en los cascos hispano-calcídicos (Graells et al. 2014) o en las cerámicas figuradas de Numancia (Jimeno et al. 2012). 
A
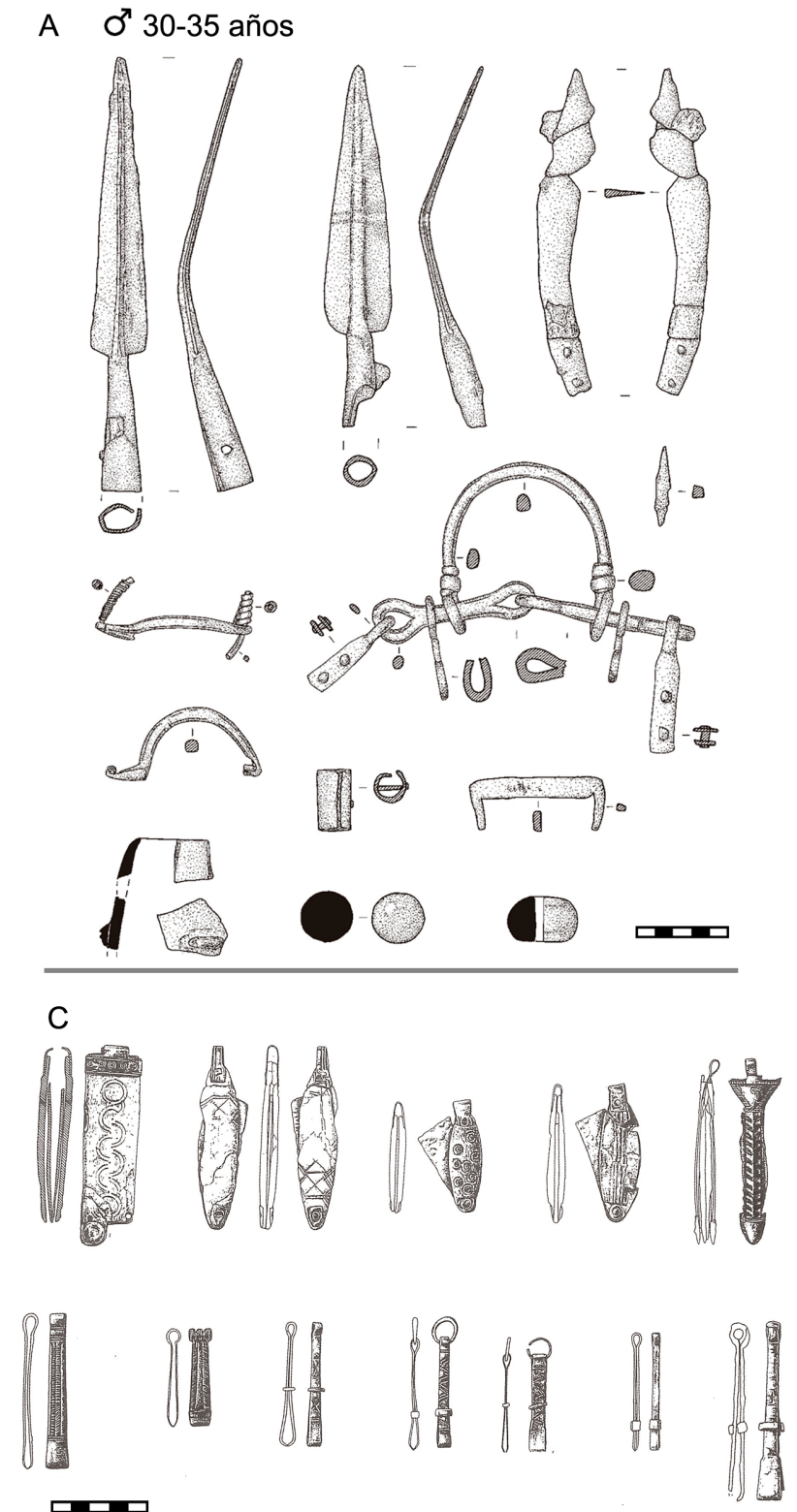

B $९$ 20-25 años
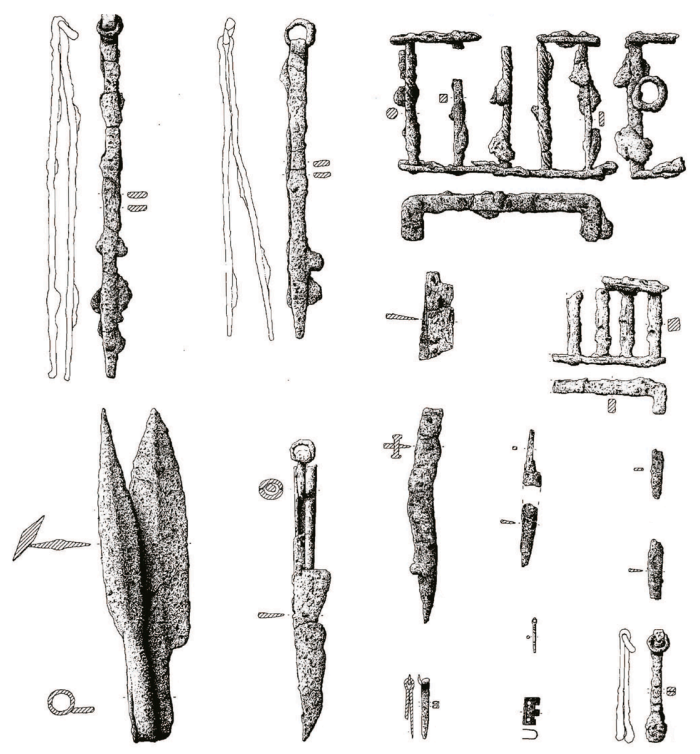

.
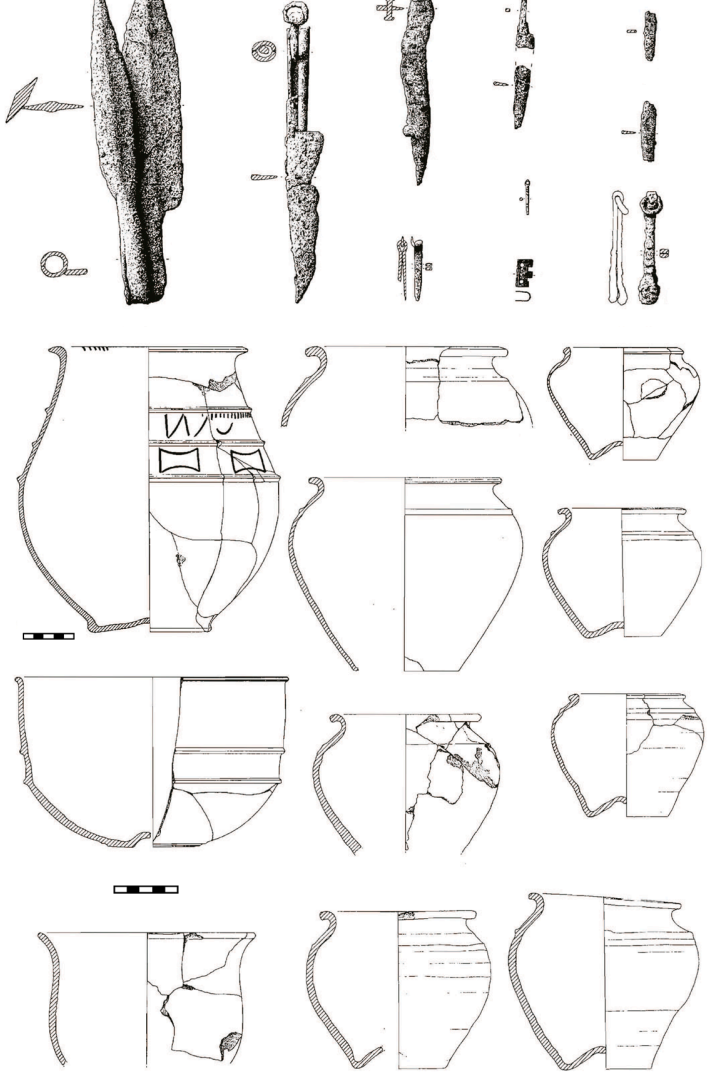

Fig. 7. Selección de ajuares de las tumbas de incineración de la meseta norte: A. guerrero de la Primera Edad del Hierro de la tumba 321 de Carratiermes (a partir de Argente et al. 2001: cd, tumba 321); B. mujer con armas y pinzas del último tercio del siglo II e inicios del I a. n. e. de la tumba 54 de Las Ruedas (a partir de Sanz Mínguez 1997: 126-127); C. navajas y pinzas decoradas de la necrópolis de El Pradillo en la Segunda Edad del Hierro (a partir de Abarquero y Palomino 2007: fig. 4).

Los equipos de aseo personal fueron otro elemento fundamental para construir esta identidad alterando la apariencia mediante el afeitado, el peinado o la depilación. Por lo general, son objetos poco comunes en los contextos domésticos, pero frecuentes en el ámbito funerario. Entre ellos destacan las pinzas de depilar, las navajas de afeitar y las tijeras de pequeño tamaño. Son frecuentes las tijeras y las pinzas en los cementerios de Carratiermes, Las Ruedas, Numancia o Viñas del Portuguí (véanse más en Ruiz Zapatero y Lorrio 2000: 281-293). En El Pradillo, las navajas de afeitar son especialmente significativas por el elevado número de ejemplares por tumba y sus características materiales, presentando cabezales o colgadores de bronce, cachas 
decoradas de hueso y hojas en hierro (Abarquero y Palomino 2007: 253) (Fig. 7C).

Las pinzas son el objeto más recurrente, realizadas en bronce o hierro, con un arete de suspensión en el extremo y con decoraciones únicas y personalizadas. Aparecen frecuentemente en ajuares con armas, pero también en ajuares sin ellas. Ello ha llevado a plantear que estarían relacionadas tanto con tumbas de hombres, como de mujeres. Esta interpretación se fundamenta principalmente en la referencia que hace Estrabón (III, $4,17)$ a partir de Artemidoro, según la cual algunas mujeres rapaban la parte delantera de sus cabezas. De ello, se deduce que usarían las pinzas de depilar para arrancar el cabello (Ruiz Zapatero y Lorrio 2000: 285), aunque una opción menos dolorosa como el uso de navajas de afeitar o similar no debiera ser descartable.

Las tumbas en las que se registran las pinzas, tijeras o navajas están mayoritariamente asociadas a varones. En Carratiermes, su presencia, al parecer exclusiva de los enterramientos masculinos, llevó a considerarlos marcadores de este género (Argente et al. 2001: 310). En Las Ruedas, también son más frecuentes en tumbas de hombres, incluyendo un enterramiento doble en la tumba 50. En cambio, en la tumba 30 se entierra a un varón y una mujer, y en la tumba 54 a una mujer de 2530 años que lleva pinzas (Fig. 7B, Tab. 3).

Los punzones serían un caso similar al anterior. También están clasificados en Carratiermes como marcadores de género masculino (Argente et al. 2001: 310) por su vinculación principal a enterramientos de varones. Sin embargo, lo contrario se registró en el enterramiento doble de la tumba 582 de Carratiermes, que corresponde a una mujer de 20-30 años y un/a niño/a de 0-1 año acompañados de un punzón biapuntado, fragmentos de espirales, un cuchillo de pequeño tama- ño, una fusayola, dos fíbulas y un posible broche de cinturón (Argente et al. 2001: 304). La funcionalidad concreta de estos objetos se discute por su polivalencia y la falta de contextos directos de empleo. Tres han sido las interpretaciones más recurrentes. Los punzones podrían haber formado parte del equipo de aseo como objetos poco especializados (Jiménez Ávila y Lorrio 2019: 320). En segundo lugar, su posible utilidad como herramienta en la fabricación de textiles. Por último, Fernández Nieto (1999: 284-286) sugiere su uso en tatuajes corporales o escarificaciones. Esta decoración es frecuente en inhumaciones de la cultura de Pazyryk, en torno al siglo V a. n. e. (Argent 2013).

\subsection{La mayoría de los ajuares, sin armas}

Entre un 56 y un $100 \%$ de los ajuares de los enterramientos meseteños no tienen armas. En conjunto van desde aquellos que carecen de objetos hasta suntuosos conjuntos de vasijas cerámicas, fusayolas, canicas, sonajas, herramientas y de adornos como fíbulas, pulseras, pectorales, collares y broches de cinturón. En los segundos, no se observa una pauta identitaria clara o generalizada identificable. Solo en Carratiermes se ha podido registrar la ausencia de canicas en las tumbas femeninas y sutiles diferencias en los adornos espiraliformes y los cuchillos curvos. Los primeros son muy comunes en este cementerio. Mientras los grandes pectorales parecen exclusivos de las tumbas masculinas (tumbas 18 y 143), las espirales de bronce, por su menor tamaño, podrían estar relacionadas con elementos decorativos presumiblemente para la ropa o fíbulas. Los cuchillos curvos, que se han relacionado con el banquete, son de menor tamaño en las tumbas femeninas que en las masculinas.

\begin{tabular}{|c|c|c|c|c|c|c|}
\hline \multirow{2}{*}{ Necrópolis } & \multirow{2}{*}{ Tumba } & \multicolumn{2}{|c|}{$1^{\mathrm{er}}$ individuo } & \multicolumn{2}{|c|}{$2^{\circ}$ individuo } & \multirow{2}{*}{ Bibliografía } \\
\hline & & Sexo & Edad & Sexo & Edad & \\
\hline \multicolumn{7}{|c|}{ Primera Edad del Hierro } \\
\hline Carratiermes & 376 & Varón & $30-40$ & & & Argente et al. 2001: cd, tumba 376 \\
\hline Carratiermes & 555 & Varón & $40-50$ & & & Argente et al. 2001: cd, tumba 555 \\
\hline Carratiermes & 23 & Varón & $40-50$ & & & Argente et al. 2001: cd, tumba 23 \\
\hline \multicolumn{7}{|c|}{ Segunda Edad del Hierro } \\
\hline Carratiermes & 330 & Varón & $30-40$ & & & Argente et al. 2001: 237-238 \\
\hline Carratiermes & 133 & Varón & $30-40$ & & & Argente et al. 2001: cd, tumba 133 \\
\hline Las Ruedas & 50 & Varón & $40-50$ & Varón & $30-40$ & Sanz Mínguez 1997: 532-541 \\
\hline Las Ruedas & 30 & Varón & $40-50$ & Mujer & $18-20$ & Sanz Mínguez 1997: 532-541 \\
\hline Las Ruedas & 54 & Mujer & $25-30$ & & & Sanz Mínguez 1997: 532-541 \\
\hline
\end{tabular}

Tab. 3. Objetos de aseo en relación al sexo, edad y cronología en enterramientos de dos necrópolis de la meseta norte.

Trab. Prehist., 78, N. ${ }^{\circ}$ 1, enero-junio 2021, pp. 121-139, ISSN: 0082-5638

https://doi.org/10.3989/tp.2021.12268 
Colgantes o collares formados de cuentas de pasta vítrea, bronce o cerámica son también muy frecuentes en los cementerios de toda la región. Incluyen piezas importadas tan significativas como la cuenta de origen fenicio de la tumba 144 de Las Ruedas, encontrada junto a más de un centenar de cuentas de vidrio azul (Sanz Mínguez y Coria 2018: 143-146). En las necrópolis situadas en las cabeceras del Alto Tajo y el Alto Jalón, las cuentas son especialmente destacables por la variedad de su materia prima (pasta vítrea, cerámica e incluso ámbar), su elevado número en algunos enterramientos y las variadas composiciones y formas (e.g. collar de Clares o la tumba 34 de Herrería III). En las tumbas de la necrópolis de Herrería III, llegaron a registrarse hasta en un 51,6\% de los ajuares, independientemente del sexo o la edad de los difuntos (Cerdeño y Sagardoy 2007: 139).

Los broches de cinturón, otro adorno de relevancia, faltan en las necrópolis de El Pradillo o La Yunta, pero se documentan en Las Ruedas, Carratiermes, Numancia y Herrería III. En contextos ibéricos y tartésicos han sido entendidos como símbolos de poder, vinculados a mujeres de alto rango y a la legitimación de los linajes (Rísquez y García Luque 2007: 266; Rísquez 2015). Esta relación se ha sugerido especialmente para los broches de tipo tartésico a partir de los datos procedentes de necrópolis como Medellín o Angorrilla (López Ambite 2008: 524, 526; Ferrer y Bandera 2014; Graells y Lorrio 2017: 136). En el cementerio de La Ruedas, los broches se han considerado indicadores del movimiento de mujeres por matrimonio de áreas próximas, como la región de los autrigones, a tierras vacceas (Sanz Mínguez 1997: 501; Sanz Mínguez y Romero 2010: 416; Sanz Mínguez y Coria 2018: 141). Sin negar que hubiera movimientos de población por alianzas matrimoniales, materializadas a través de objetos exógenos en los enterramientos. En Las Ruedas, las placas de cinturón aparecen mayoritariamente en las tumbas femeninas $\left(\mathrm{n}^{\circ}{ }^{\circ} 22,25,29,31,122\right)$, pero también las hay en las de varones (tumba 27). Datos similares presenta Herrería III con 22 broches en 21 enterramientos (Cerdeño y Sagardoy 2007: 129). Según las analíticas osteológicas, 4 tumbas de mujeres y 2 de varones (una simple y otra doble) presentaban piezas de cinturón. En Carratiermes, su distribución entre mujeres y hombres parece más equilibrada sin apreciar grandes diferencias entre las tipologías. De los 84 elementos de cinturón recuperados, solo 37 proceden de contextos cerrados (Argente et al. 2001: 100-101), y se pudo determinar el sexo y la edad de los individuos que se enterraron con 18 de estos objetos (11 piezas de engarce, 2 pasadores de la hebilla y 5 refuerzos de cinturón) (Fig. 8).

\section{4. ¿Diademas? ¿elementos de tocado? ¿soportes?}

Desde las investigaciones del marqués de Cerralbo (Aguilera y Gamboa 1915: 61-62), las llamadas "diademas" o "soportes para tocado" han sido asociadas a las mujeres en la documentación arqueológica del siglo XX. La interpretación de estos objetos procede principalmente de la cita de Artemidoro, recogida por Estrabón (III, 4, 17), sobre los tocados de las mujeres del norte de la península ibérica donde se las atribuía un tipo de tocado modelado con ganchos de hierro doblado sobre el que colgaba el velo. Con el paso de los años, y por la dudosa funcionalidad de estos artefactos, W. Schüle (1969: 161 y 236) recurrió a una denominación más genérica: "horquillas dobles de hierro".

En la meseta, estos objetos son frecuentes en necrópolis de excavaciones antiguas como Arcóbriga, Clares, Aguilar de Anguita, Viñas del Portuguí (Osma) o Las Quintanas (Gormaz) (ampliado en Chordá y Pérez Dios

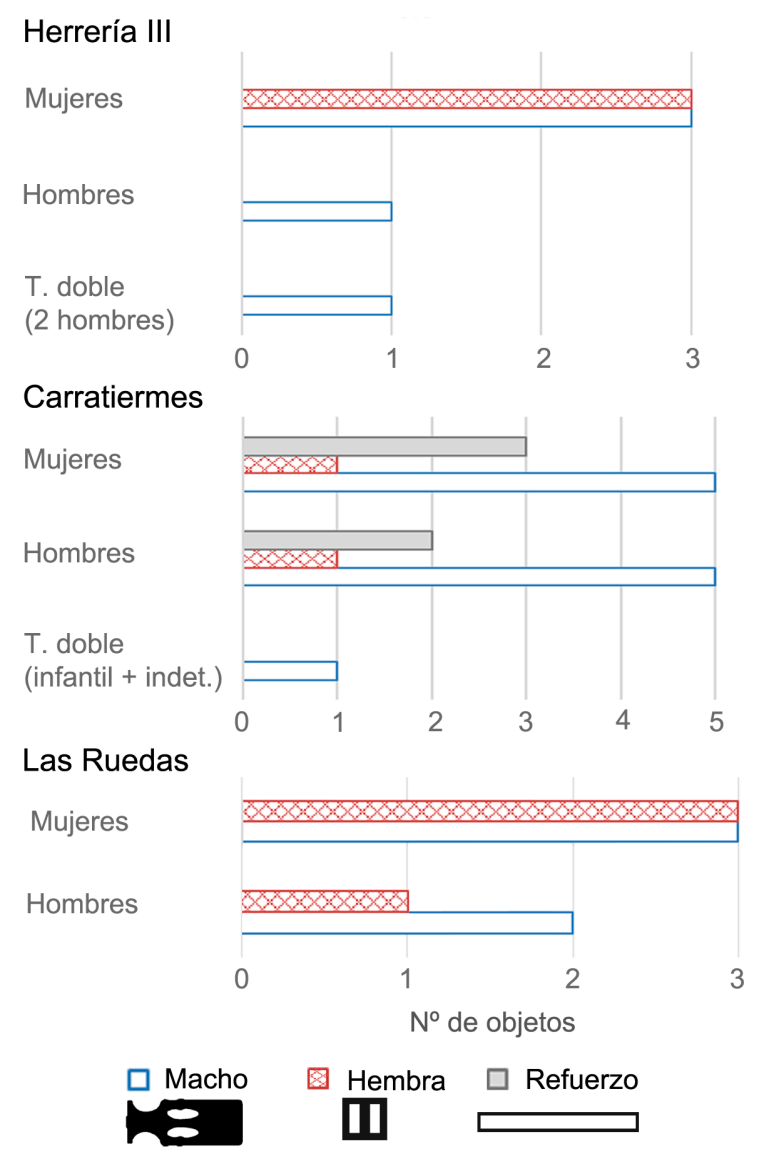

Fig. 8. Distribución de los broches de cinturón por sexo y edad en las necrópolis de incineración de la meseta norte estudiadas. En color en la edición electrónica. 
2014; Cerdeño y Chordá 2017: 53). Sus contextos plantean interrogantes, por lo que su dación ha sido puesta en cuestión. Según las excavaciones de Chera, El Inchidero, Herrería III, Puente de la Sierra (Checa) y La Cerrada de los Santos, se fechan entre los siglos VII y IV a. n. e. para la región del Alto Tajo-Alto Jalón (Arenas 1999: fig. 43; Chordá y Pérez Dios 2014: 407). Al mismo tiempo, en la exhaustiva revisión de los materiales de Arcóbriga (Lorrio y Sánchez de Prado 2009: 361-367), necrópolis que concentra estos artefactos en mayor número, algunos se han fechado entre los siglos III e inicios del II a. n. e. por su asociación con fíbulas zoomorfas (tumbas $\mathrm{G}$ y J). Esta última cronología se asemeja a los ejemplares registrados en el Alto Duero (Gormaz y Osma) (Lorrio 2005: 223). Allí, destaca el caso singular de la necrópolis de Numancia, donde aparecieron alambres metálicos que también podrían haber sido utilizados como armazones para elevar el velo, como refleja la iconografía de sus cerámicas (Jimeno et al. 2004: 225-227).

Las características biológicas de los individuos enterrados con estos soportes se conocen solo en dos necrópolis. En Herrería III, el sexo de los individuos solo se documentó en 2 tumbas $\left(\mathrm{n}^{\circ}{ }^{\circ} 30,47\right)$ de las 10 que los tenían (Cerdeño y Sagardoy 2007: tab. 9, 138). Corresponden a dos mujeres jóvenes que completaban sus ajuares con cuentas de collar, pulseras y otros adornos. En la necrópolis de Inchidero, los soportes se registraron en las tumbas C3G13T1, C3T12 y C5T9. Las dos últimas tienen cuatro y tres individuos, respectivamente (Arlegui 2012, 2014). Las dos tumbas de Herrería III ofrecen datos claros sobre la asociación de los soportes con mujeres, no obstante, harán falta más datos para confirmar su utilidad y su asociación con ellas.

\subsection{Herramientas}

Los artefactos relacionados con la producción textil doméstica (agujas y fusayolas), agrícola (hoces y zapapicos), ganadera (tijeras de esquilar) y la explotación de los bosques (tijeras de podar) aparecían en los ajuares antes del siglo IV a. n. e. Sin embargo, serán característica a partir de dicho siglo, junto a una significativa reducción del armamento.

Los útiles de producción doméstica fueron muy significativos en necrópolis como Numancia, donde las agujas de bronce y hierro aparecieron hasta en el $18 \%$ de los enterramientos (Jimeno et al. 2004: fig. 210a y $210 \mathrm{~b}$ ). Las fusayolas, tradicionalmente y a falta de análisis osteológicos, han sido asociadas a las mujeres (Fernández Gómez 1986: 830; Cuadrado 1987) a las que se atribuyen las actividades domésticas y textiles.

Las fusayolas no eran desconocidas durante la Primera Edad del Hierro en los ajuares de la meseta, pero su número se incrementó entre finales del siglo IV y el II a. n. e. La necrópolis de La Yunta con 109 reúne la mayor colección. Según los análisis osteológicos se distribuyen en torno al $50 \%$ entre hombres y mujeres (García Huerta 2013-2014: 318), siendo mayoritarias en las tumbas infantiles (tumbas 61 y 88) (García Huerta y Antona 1992: 136). En la necrópolis de Sigüenza, tenían fusayolas una mujer de 60 años, otra entre 40-50 años y un varón de 35-40 años (Cerdeño y Pérez de Ynestrosa 1993). En Carratiermes, se documentó una fusayola en la tumba 138 de una mujer de 20-30 años y otras tres decoradas en la tumba 175 de un infante de 1-2 años. En Las Ruedas, cinco fusayolas se distribuían entre cuatro tumbas: un infantil entre 8-10 años (tumba 13) y tres mujeres (tumbas 2, 11 y 122) (Sanz Mínguez 1997: 345-346; Sanz Mínguez y Diezhandino 2007). De nuevo, vemos como las fusayolas tampoco supusieron un marcador de género o edad en la meseta.

Las hoces o tijeras de gran tamaño (esquilado), relacionadas con tareas agro-ganaderas, incrementaron

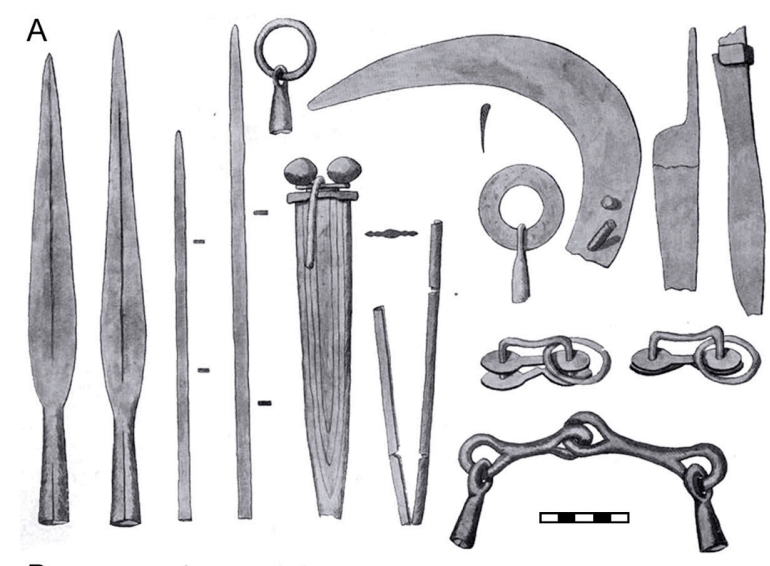

B

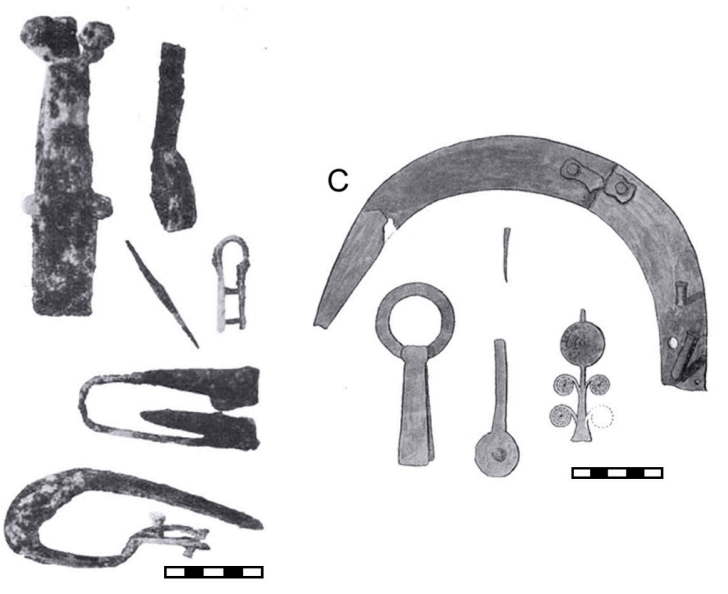

Fig. 9. Ajuares de La Mercadera con herramientas: A. Tumba 14; B. Tumba 68; C. Tumba 6 (a partir de Taracena 1932: 27, láms. VI, XIV, XI). 

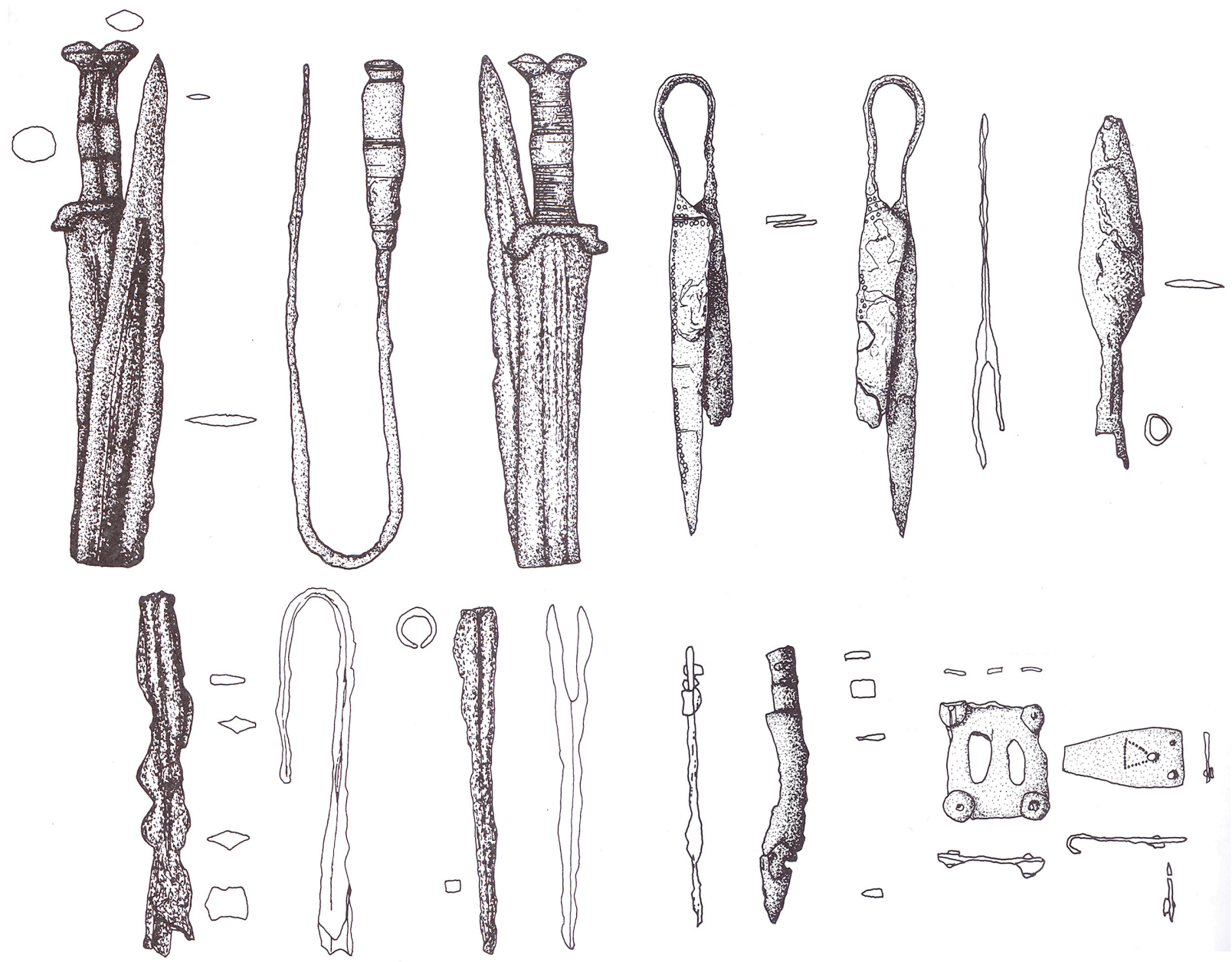

Fig. 10. Tumba 15 de Viñas del Portuguí de la colección del Museo Arqueológico Nacional (a partir Fuentes Mascarell 2004: fig. 18-19).

su protagonismo durante la Segunda Edad del Hierro. Las necrópolis del Alto Duero las vinculan claramente con el armamento. En La Mercadera (tumbas 1, 3, 6, $14,16,19,68,76,78,80$ y 98), su número varía entre cinco hoces y ocho (Taracena 1932: 18) o nueve tijeras (Lorrio 1990: fig. 2), dos de ellas descontextualizadas. En todas las tumbas los ajuares incluían armas. En cuatro, destacan las espadas de antenas atrofiadas y en la tumba 6 una hoz reparada con un remache (Fig. 9).

Las tijeras, como las agujas, eran muy numerosas en Numancia y distribuidas por todo el cementerio. Las hoces, en cambio, se registraron solo en las tumbas 103, 132 y 139 , en combinación variable con arreos de caballo, puñales y cuchillos rectos o curvos (Jimeno et al. 2004: fig. 208). La tumba 144 contenía en el ajuar una podadera y, de nuevo, numerosas armas, arreos de caba1lo, una espuela y elementos de aseo personal y de ador- no, como fíbulas o apliques hemiesféricos de bronce (Jimeno et al. 2004: fig. 108a y 108b). Esta asociación de armas y herramientas se repite en las Viñas del Portuguí, donde superando los problemas de asociación de los ajuares (García Merino 2000: 139; Fuentes Mascarell 2004), los asignables a las tumbas 1 y 15 de la colección del Museo Arqueológico Nacional (Madrid) pudieron ser reconstruidos. Constan de herramientas (alcotana y unas tijeras decoradas), sendas espadas de antenas atrofiadas, otras armas y ornamentos (Fig. 10). En El Pradillo (Pinilla de Trasmonte), se registraron tres hoces, una con cierta decoración en el mango y una arandela de suspensión (Abarquero y Palomino 2007: fig. 4-15 y 16; Moreda y Nuño 1990: 174).

Las composiciones de los ajuares de la necrópolis de Carratiermes eran similares a las ya presentadas. Se documentaron nueve tijeras en siete tumbas $\left(n .^{\circ} 6\right.$, 
$16,27,149,208,263,510)$, junto a vasijas torneadas, arreos de caballo y lanzas (Argente et al. 2001: 128129). En las tumbas con ajuar solo pudo identificarse el sexo, dos varones (n. ${ }^{\circ} 6$ y 263 ) y la edad de tres individuos: sujetos entre 30 y 40 años (tumbas 6,149 ) y un varón entre 60 y 70 años (tumba 263).

Como en el anterior caso de los soportes de tocado, únicamente se ha podido determinar el sexo de dos individuos varones. En este caso, les acompañaban herramientas agrícolas, ganaderas o forestales. Sin embargo, harán falta nuevos datos para precisar el papel como marcador de género asignable a estas piezas.

\subsection{Honrando a los muertos: el banquete funerario y las ofrendas}

Los restos de fauna, las vasijas cerámicas, las pinzas de carne, las parrillas o los cuchillos curvos han sido vinculados al banquete. Estos artefactos son frecuentes en tumbas de individuos de todas las características y estarían relacionados con dos momentos fundamentales de los rituales funerarios: las exequias fúnebres y las ofrendas a los antepasados.

Los huesos de animales son recurrentes en todas las necrópolis. En La Yunta, se documentan en el $12 \%$ de los enterramientos (García Huerta y Antona 1992); en Las Ruedas, en el 21,8 \% (a partir de Sanz Mínguez 1997: 484); en Sigüenza, en el 30 \% (Cerdeño y Pérez de Ynestrosa 1993); en Herrería III, en el 40 \% (Cerdeño y Sagardoy 2007: 118-119) y en Numancia, en el $44,5 \%$ (Jimeno et al. 2004). Las taxonomías animales más frecuentes en el Alto Tajo-Jalón fueron los bóvidos, los ovicápridos, los cérvidos y las aves (Cerdeño 2010; Sagardoy y Chordá 2010). En Las Ruedas destacaron el cordero, el conejo y el cerdo (Sanz Mínguez y Romero 2010: 406) y en Numancia, los ovicápridos y los équidos (Jimeno et al. 2004).

Las vajillas cerámicas son otro buen testimonio de estas prácticas por su generalizada resistencia al paso del tiempo y la cantidad y variedad de sus tipos. Las vasijas depositadas como parte del ajuar o como ofrenda no fueron exclusivas de la dimensión funeraria. Tampoco fueron realizadas ex profeso para ella, sino que como la mayoría de objetos de ajuar eran de uso cotidiano (Lorrio 2005: 133). Las cerámicas de La Yunta, p. ej., presentan huellas de uso y mellados. Es especialmente significativo que los recipientes con asas, solo las conserven ocasionalmente (García Huerta y Antona 1992: 147; García Huerta 2013-2014: 301). Otros artefactos como la hoz de la tumba 6 de La Mercadera (Taracena 1932: 27, láms. VI, XIV, XI), las dos fíbulas de las tumbas 23 y 84 de La Yunta (García Huerta y Antona 1992: $36,83-84$ ) o la jarra trilobulada de la tumba 56 de Las
Ruedas (Sanz Mínguez 1997: 129-131) estaban reparadas con remaches o lañas metálicas.

Joanna Sofaer (2000: 397-398) se planteaba la necesidad de diferenciar los objetos personales de los difuntos -aquellos con los que habrían convivido y tendrían un significado intrínseco en la construcción de su identidad personal-, y los objetos aportados por otros miembros de la comunidad en los rituales funerarios. Estos tendrían una agenda social y política propia. El ritual de la cremación, empleado en las necrópolis de la meseta, complica mucho la determinación de esas diferencias materiales, pero la identificación de artefactos con huellas de reparación o uso podría sugerir significados de los mismos más allá del uso meramente práctico.

Objetos como las parrillas, pinzas de carne y trébedes, hallados en Las Ruedas, y el cazo y colador de bronce en Carratiermes se asocian tradicionalmente a la figura de los guerreros y a la importancia del banquete $\mathrm{y}$ al consumo de alcohol en eventos sociales para sellar, reforzar o celebrar relaciones clientelares o de hospitalidad. Pero, una vez más, ese nexo no es unívoco. Esas piezas aparecen en tumbas masculinas, femeninas y de infantiles, de cualquier edad. Destacan en Las Ruedas los enterramientos 127 a de una mujer adulta y $127 \mathrm{~b}$ de una niña de no más de 8 años. Sus abundantes ajuares se componían de pinzas de hierro para carne, parrillas miniaturizadas y unos amplísimos conjuntos cerámicos (Sanz Mínguez y Romero 2010). La generalización de estos objetos en los ajuares estaría relacionada, con el importante papel social que jugaron las prácticas de comensalidad en el ámbito funerario como escenario de la negociación social de identidades colectivas relacionadas con el estatus, la casa y la familia.

\section{REFLEXIONES FINALES}

La Arqueología de la muerte aún afronta el gran reto de entender las estructuras sociales del pasado a través de las Arqueologías del cuerpo y de la identidad. Según los datos analizados en este artículo, a lo largo de la Edad del Hierro se aprecian dos tendencias fundamentales que coinciden con las dos fases principales del periodo. Entre los siglos VI y IV a. n. e., los principales protagonistas de los ajuares son las armas y los ornamentos. La composición y los tipos de objetos que formaron estos ajuares dependieron de las diferencias étnicas y regionales desde una predominancia de las panoplias armamentísticas en el Alto Duero (compuestas por dos lanzas, un cuchillo curvo, escudos y arreos de caballo), a los tahalíes y puñales tipo Monte Bernorio en el valle medio del Duero, y las lanzas y espadas en las cabeceras del Alto Tajo y Alto Jalón. También en los ornamentos se aprecian diferencias regionales 
como el gusto por los pectorales, fíbulas y elementos decorativos espiraliformes en las necrópolis del Alto Duero en contraposición de los collares de cuentas cerámicas de las cabeceras del Tajo y el Jalón.

Por el contrario, a finales del siglo IV a. n. e., las decoraciones se generalizaron en las armas, los equipos de aseo personal y las herramientas. El diseño y los ornamentos debieron dotar a los objetos de propiedades mágicas para proteger a sus portadores, así como de poderes sobrenaturales para intimidar a los enemigos y/o sustentar la preeminencia social de su propietario (González Ruibal et al. 2011). A esto se añade, una reducción generalizada del número de armas en los ajuares, en los que las amplias panoplias de hasta 7-8 objetos se limitan a la presencia de algún puñal, vaina o regatón (bien caracterizado por Lorrio 2005: fig. 59, 2016). Las formas cerámicas comenzaron a protagonizar los ajuares, incluyendo combinaciones de formas, decoraciones y producciones a mano y a torno, aunque primaron las torneadas. En este cambio en la forma de negociación de las identidades ante la muerte, los ideales de la guerra y del guerrero continuaron, pero se vieron matizados por objetos relacionados con la comensalidad y la producción agro-ganadera. En la Europa templada, esta transformación ha sido asociada a un cambio en los valores de la guerra, mezclando el paradigma de violencia con el hombre de negocios (Danielisová 2014: 81). Este controla la producción y/o el flujo de determinados bienes o recursos, en relación con otras fuentes de riqueza como la tierra, los animales o la producción doméstica.

Durante toda la Edad del Hierro los cambios en los tipos, formas y decoraciones de los objetos de los ajuares dentro de cada periodo acompañaron indistintamente a varones y a mujeres, independientemente de su edad. Las armas, a las que la investigación prestó tanta atención asociándolas a los enterramientos masculinos, fueron en este contexto bienes de prestigio en una sociedad donde la violencia física y simbólica eran efectivas estrategias de poder. Un poder procedente de múltiples fuentes, interrelacionado con la reputación personal, los linajes familiares, las unidades domésticas, las capacidades productivas, el control de recursos o el conocimiento, entre otros aspectos.

Los principios organizadores de las sociedades del pasado son, por lo tanto, complejos de desentrañar desde nuestros marcos conceptuales presentes. Sin embargo, es interesante mencionar el caso del cementerio de Heuneburg (suroeste de Alemania). Allí, a partir de los análisis materiales y osteológicos de los ajuares, se determinó que la edad era la categoría social que actuaba como principio vertebrador del contenido de los ajuares funerarios, mientras que el género debía ser tratado como una variable dependiente, junto al estatus y el papel social (Arnold 2016: 850). Por el contrario, en la meseta, las diferencias en las composiciones de los ajuares entre infantiles y adultos o entre adultos jóvenes y ancianos son imperceptibles, sin materiales determinantes, ya sean tumbas simples o enterramientos colectivos. Lo mismo ocurre con el género. A la luz de los datos, los ejes vertebradores de las comunidades meseteñas parecen estar más relacionados con los desarrollos personales de los difuntos en vida y el estatus personal y familiar que con la edad o el género. Más allá de las diferencias regionales no se han identificado marcadores de edad o género a partir de los datos actuales. No obstante, este estudio es tan solo un punto de partida y será interesante continuar indagando sobre estos conceptos en investigaciones futuras con nuevos marcos teóricos, registros detallados de excavación y analíticas óseas.

\section{AGRADECIMIENTOS}

A Alba Comino y Sergio Quintero por su apoyo y sus comentarios a un borrador de este artículo. Jesús Liceras y Ascensión Garrido prestaron una ayuda indispensable para consultar bibliografía y enviar notas personales a distancia en tiempos de cuarentena y COVID-19. Los/as revisores/as y el equipo editorial aportaron valiosos comentarios que han enriquecido el contenido de este trabajo. Cualquier error es responsabilidad de la autora.

\section{BIBLIOGRAFÍA}

Abarquero, F. J. y Palomino, A. L. 2007: “La necrópolis de El Pradillo, Pinilla-Trasmonte (Burgos). Evolución de los ritos funerarios en el confín del territorio celtibérico". En J. Morín, D. Urbina y N. Ferreira (eds.): As Idades do Bronze e do Ferro na Península Ibérica. Actas do IV Congresso de Arqueología Peninsular (Faro 2004): 249-262. Faro.

Aguilera y Gamboa, E. 1915: "Las necrópolis ibéricas". Asociación Española para el Progreso de las Ciencias (Valladolid 1915) II, Conferencias de las secciones: $\mathrm{s}$. n. Madrid

Alarcón, E. y Sánchez Romero, M. 2015: “Arqueología feminista, de las mujeres y del género en la Prehistoria de Andalucía". Menga: Revista de prehistoria de Andalucía 6: 33-59.

Arenas, J. A. 1999: La Edad del Hierro en el Sistema Ibérico Central, España. British Archaeological Reports International Series 780, BAR Publishing. Oxford.

Arenas, J. A. y Cortés, L. 1997: "Mortuary rites in the Celtiberian cemetery of Aragoncillo (Guadalajara, Spain)". En W. H. Waldren, J. A. Ensenyat and R. C. Kennard (eds.): Ritual rites and religion in Prehistory: IIIrd Deya International Conference of Prehistory (Deya 1994). Vol. II. British Archaeological Reports International Series 611, Tempus Reparatum. Oxford. Oxford: 1-20.

Argent, G. 2013: "Inked: human-horse apprenticeship, tattoos, and time in the Pazyryk world". Society \& Animals 21: 178-193. https://doi.org/10.1163/15685306-12341301

Argente, J. L. 1976: "Informe sobre las excavaciones efectuadas en la necrópolis de 'El Altillo'. Aguilar de Anguita (Guadalajara)". Noticiario Arqueológico Hispano 5: 355-360.

Argente, J. L. 1977: “La necrópolis celtibérica de 'El Altillo' en Aguilar de Anguita (Guadalajara)". Wad-Al-Hayara 4: 99-141. 
Argente, J. L.; Díaz, A. y Bescós, A. 2001: Tiermes V, Carratiermes. Necrópolis celtibérica. Memorias Arqueología en Castilla y León 9, Junta de Castilla y León. Valladolid. Incluye CD-ROM "Necrópolis de Carratiermes: el mundo celtibérico en la meseta oriental" con información complementaria sin datos editoriales, ni paginación.

Arlegui, M. 2012: "La necrópolis celtibérica del Inchidero (Aguilar de Montuenga, Soria): estratigrafía, cronotipología y dataciones radiocarbónicas". Complutum 23 (1): 181-201. https://doi.org/10.5209/rev_CMPL.2012.v23.n1.39537

Arlegui, M. 2014: "La necrópolis del Inchidero, Aguilar de Montuenga, Soria". En F. Burillo y M. Chordá (eds.): VII Simposio sobre los Celtíberos: nuevos hallazgos, nuevas interpretaciones (Daroca 2012): 379-386. Teruel.

Arnold, B. 1991: "The deposed princess of Vix: the need for an engendered European Prehistory". En D. Walde y N. Willows (eds.): The archaeology of gender. University of Calgary Archaeological Association. Calgary: 366-374.

Arnold, B. 2016: "Belts vs. blades: the binary bind in Iron Age mortuary contexts in Southwest Germany". Journal of Archaeological Method and Theory 23 (3): 832-853. https://doi.org/10.1007/s10816-016-9289-8

Arnold, B. y Wicker, N. (eds.) 2001: Gender and the archaeology of death. AltaMira Press. Walnut Creek.

Barrio Martín, J. 2006: La necrópolis celtibérica de La Dehesa de Ayllón: fondos del Museo de Segovia. Estudios y Catálogos 16, Junta de Castilla y León. Valladolid.

Belar, Ch. 2017: Pour une archéologie du genre. Les femmes en Champagne à l'âge du Fer. Historie et Archéologie, Hermann. París.

Cabré, J. 1916-1917: Catálogo Monumental de la provincia de Soria 3 [Manuscrito]. CSIC. https://csic.primo.hosted.exlibrisgroup.com/ permalink/f/homi3k/34CSIC_ALMA_DS21110091280004201 (consulta junio 2020).

Cerdeño, M. L. 1981: "La necrópolis de Molina de Aragón”. Wad-AlHayara 8: 9-84.

Cerdeño, M. L. 1983: "Nuevos ajuares de la necrópolis de Molina de Aragón (Guadalajara)". Wad-Al-Hayara 10: 283-294.

Cerdeño, M. L. 2010: "Veinte años después: el ritual funerario de los Celtíberos del Alto Tajo-Alto Jalón”. En F. Burillo (ed.): Ritos y mitos. VI Simposio sobre los Celtiberos (Daroca 2008). Centro de Estudios Celtibéricos de Segeda. Mara: 315-330.

Cerdeño, M. L. y Chordá, M. 2017: "Hierros antiguos en la Meseta oriental: la Celtiberia olvidada". Cuadernos de Prehistoria y Arqueología de la UAM 43: 47-65. https://doi.org/10.15366/cupauam2017.43.003

Cerdeño, M. L. y García Huerta, M. R. 1992: El castro de La Coronilla. Chera, Guadalajara (1980-1986). Excavaciones Arqueológicas en España 163, Ministerio de Cultura. Madrid.

Cerdeño, M. L. y García Huerta, M. R. 2001: "Las necrópolis celtibéricas: nuevas perspectivas de estudio". En R. García Huerta y J. Morales (eds.): Arqueología funeraria: las necrópolis de incineración. Ediciones de la Universidad de Castilla-La Mancha. Cuenca: 141-190.

Cerdeño, M. L. y Pérez de Ynestrosa, J. L. 1993: La necrópolis celtibérica de Sigüenza: revisión del conjunto. Seminario de Arqueología y Etnología Turolense. Teruel.

Cerdeño, M. L. y Sagardoy, T. 2007: La necrópolis celtibérica de Herrería III y IV (Guadalajara). Fundación Segeda, Centro de Estudios Celtibéricos y Junta de Castilla-La Mancha. Toledo.

Chapa, T. 2003: "La percepción de la infancia en el mundo ibérico". Trabajos de Prehistoria 60 (1): 115-138. https://doi.org/10.3989/tp.2003.v60.i1.125

Chordá, M. y Pérez Dios, P. 2014: "Las supuestas 'diademas femeninas', un ejemplo para revisión”. En F. Burillo y M. Chordá (eds.): VII Simposio sobre los Celtíberos: nuevos hallazgos, nuevas interpretaciones. Teruel: 405-412.

Conkey, M. y Spector, J. 1984: "Archaeology and the Study of Gender". Advances in Archaeological Method and Theory 7: 1-38. https://doi.org/10.1016/B978-0-12-003107-8.50006-2

Cruz Berrocal, M. 2009: "Feminismo, teoría y práctica de una arqueología científica". Trabajos de Prehistoria 66 (2): 25-43. https://doi.org/10.3989/tp.2009.09026

Cuadrado, E. 1987: La necrópolis ibérica de El Cigarralejo (Mula, Murcia). Bibliotheca Praehistorica Hispana 23, CSIC. Madrid.
Danielisová, A. 2014: “Oppida, production and social status. Complexity of the Late La Tène Period in Central Europe". En M. Fernández Götz, H. Wendling y K. Winger (eds.): Paths to complexity. Centralisation and urbanisation in Iron Age Europe. Oxford Books. Oxford: 76-83.

Dechelette, J. 1913: Manuel d'archéologie préhistorique, celtique et gallo-romaine. II Archéologie celtique ou protohistorique, 2e partie. Premier Âge du Fer ou époque de Hallstatt. Librarie Alphonse Picard et fils. París.

Díaz Andreu, M. 2005: “Gender identity”. En M. Díaz Andreu, S. Lucy, S. Babić y D. N. Edwards (eds.): The archaeology of identity: approaches to gender, age, status, ethnicity and religion. Routledge. Londres: 13-42.

Díaz Andreu, M. y Montón Subías, S. 2013: “Gender and feminism in the prehistoric archaeology of southwest Europe". En D. L. Bolger (ed.): A companion to gender prehistory. Wiley-Blackwell. Oxford: 438-457. https://doi.org/10.1002/9781118294291.ch21

Fernández Gómez, F. 1986: Excavaciones arqueológicas en el Raso de Candeleda, I-II. Diputación Provincial, Institución "Gran Duque de Alba". Ávila.

Fernández Nieto, F. J. 1999: "Interpretaciones en materia religiosa, social y técnica sobre los pueblos antiguos de la Península Ibérica". En A. Alonso (ed.): Homenaje al profesor Montenegro: estudios de Historia Antigua. Universidad de Valladolid. Valladolid: 275-292.

Ferrer, E. y Bandera, M. L. de la 2014: "Los broches de cinturón”. En A. Fernández, A. Rodríguez, M. J. Casado y E. Prados (eds.): La necrópolis de época tartésica de La Angorrilla, Alcalá del Río, Sevilla. Universidad de Sevilla. Sevilla: 403-428.

Fuentes Mascarell, C. 2004: La necrópolis celtibérica de Viñas del Portuguí (Osma, Soria). Ed. Toxosoutos. Galicia.

García Huerta, M. R. 2013-2014: "Las fusayolas de la necrópolis celtibérica de La Yunta (Guadalajara)". Kalathos 26-27: 297-322.

García Huerta, M. R. y Antona, V. 1992: Excavaciones arqueológicas: La Yunta, Guadalajara. Campañas 1984-1987. Servicio de Publicaciones de la Junta de Comunidades de Castilla-La Mancha. Toledo.

García Merino, C. 2000: "Acerca de las necrópolis de Uxama Argaela". En E. Baquedano (ed.): Soria arqueológica: a José Luis Argente Oliver. Diputación Provincial de Soria. Soria: 131-164.

García Soto, E. 1982: "La necrópolis celtibérica de Ucero (Soria)". Arevacon $1:$ : 4 -9.

Gero, J. y Conkey, M. W. (eds.) 1991: Engendering archaeology: women and Prehistory. Wiley-Blackwell. Oxford.

González Ruibal, A.; Hernando, A. y Politis, G. 2011: “Ontology of the self and material culture: arrow-making among the Awa hunter-gatherers (Brazil)". Journal of Anthropological Archeology 30 (1): 1-16. https://doi.org/10.1016/j.jaa.2010.10.001

Graells, R. 2012: "Discos-coraza de la Península Ibérica (s. VI-IV aC)". Jahrbuch des Römisch-Germanisches Zentralmuseums 59 (1): 85244.

Graells, R. y Lorrio, A. 2017: Problemas de cultura material: broches de cinturón decorados a molde de la Península Ibérica (s. VII-VI a.C.). Publicacions de la Universitat d'Alacant. Alicante.

Graells, R.; Lorrio, A. y Quesada, F. 2014: Cascos hispano-calcídicos. Símbolos de las élites guerreras celtibéricas. Römisch-Germanisches Zentralmuseum. Maguncia.

Gusi, F. y Muriel, S. 2008: "Panorama actual de la investigación de las inhumaciones infantiles en la Protohistoria del sudoeste mediterráneo europeo". En F. Gusi, S. Muriel y C. R. Olaria (eds.): Nasciturus, infans, puerulus vobis mater terra: la muerte en la infancia. Diputación de Castellón. Castellón: 257-330.

Hernando, A. 2002: Arqueología de la Identidad. Akal. Madrid.

Hernando, A. 2012: La fantasía de la individualidad. Sobre la construcción sociohistórica del sujeto moderno. Katz. Madrid.

Izquierdo, I. 2007: "Arqueología de la muerte y el estudio de la sociedad: una visión desde el género en la Cultura Ibérica”. Complutum 18: 247-261. https://revistas.ucm.es/index.php/CMPL/article/view/ CMPL0707110247A

Jiménez Ávila, J. y Lorrio, A. 2019: "Sets de tocador: aspectos generales y problemas particulares de su presencia en la península ibérica durante la Edad del Hierro". Complutum 30 (2): 313-341. https://doi.org/10.5209/cmpl.66336 
Jimeno, A.; Chaín, A.; Quintero, S.; Liceras Garrido, R. y Santos, A. 2012: "Interpretación estratigráfica de Numancia y ordenación cronológica de sus cerámicas". Complutum 23 (1): 203-218. https://doi.org/10.5209/rev_CMPL.2012.v23.n1.39538

Jimeno, A.; Torre, J. I. de la; Berzosa, R. y Martínez Naranjo, J. P. 2004: La necrópolis celtibérica de Numancia. Memorias de Arqueología en Castilla y León 12, Junta de Castilla y León. [Carbajosa de la Sagra, Salamanca].

López Ambite, F. 2008: "Broches de cinturón". En M. Almagro Gorbea (ed.): La necrópolis de Medellín II. Estudio de los hallazgos. Bibliotheca Archaeologica Hispana 26 (2), Real Academia de la Historia. Madrid: 513-528.

Lorrio, A. 1990: "La Mercadera (Soria): organización social y distribución de la riqueza en una necrópolis celtibérica". En F. Burillo (ed.): Necrópolis celtibéricas. II Simposio sobre los Celtiberos (Daroca 1988): 39-50. Zaragoza.

Lorrio, A. 2005: Los Celtiberos. Real Academia de la Historia, Universidad Complutense de Madrid, Universitat d'Alacant. Madrid, Alicante. Madrid.

Lorrio, A. 2016: "La guerra y el armamento celtibérico: estado actual". En R. Graells y D. Marzoli (eds.): Armas de la Hispania prerromana. RGZM-Tagungen 24. Maguncia:229-337.

Lorrio, A. y Sánchez de Prado, M. D. 2009: La necrópolis celtibérica de Arcóbriga. Monreal de Ariza, Zaragoza. Caesaraugusta 80, Institución Fernando el Católico. Diputación de Zaragoza. Zaragoza.

Montón Subías, S. y Lozano Rubio, S. 2012: "La arqueología feminista en la normativa académica". Complutum 23 (2): 163-176. https://doi.org/10.5209/rev CMPL.2012.v23.n2.40883

Moreda, J. y Nuño, J. 1990: “Avance al estudio de la necrópolis de la Edad del Hierro de "El Pradillo". Pinilla de Trasmonte (Burgos)". En F. Burillo (ed.): Necrópolis celtibéricas. II Simposio sobre los Celtíberos (Daroca 1988): 171-181. Zaragoza.

Morenas de Tejada, R. 1916a: "Hallazgos arqueológicos en España. La necrópolis ibérica de Gormaz". Por esos mundos, enero: 169-175.

Morenas de Tejada, R. 1916b: "Divulgaciones arqueológicas. Las ruinas de Uxama". Por esos mundos, octubre: 605-610.

Moreno Ojeda, L. 2019: "Los infantes y la muerte en la antigua Celtiberia”. Arpi. Arqueología y Prehistoria del Interior Peninsular 8: 67-85.

Orozco-Köhler, T. 2016: "El proceso de producción lítica en las sociedades prehistóricas. Reflexiones desde una perspectiva de género". En A. Delgado y M. Picazo (eds.): Los trabajos de las mujeres en el mundo antiguo. Cuidado y mantenimiento de la vida. Serie Hic et Nunc 8, Institut Català d'Arqueologia Clàssica. Tarragona: 17-22.

Parker-Pearson, M. 1993: "The powerful dead: archaeological relationship between the living and the dead". Cambridge Archaeological Journal 3 (2): 203-229. https://doi.org/10.1017/S0959774300000846

Prados, L. 2011: "Género e identidad en los contextos funerarios ibéricos (siglos V-I a.C.)". En L. Prados (ed.): Arqueología y género: mujer y espacio sagrado: haciendo visible a las mujeres en los lugares de culto de la época ibérica. Universidad Autónoma de Madrid. Madrid: 201-217.

Prados, L. 2011-2012: "El ritual funerario durante la II Edad del Hierro en la península ibérica. Algunas reflexiones sobre los grupos marginados por la investigación". Cuadernos de Prehistoria y Arqueología, 37-38: 317-331. https://doi.org/10.15366/cupauam2012.38.016

Querol, M. A. y Triviño, C. 2004: La mujer en "El origen del hombre". Bellaterra. Barcelona.

Quesada, F. 2010: "Las armas de la sepultura 155 de la necrópolis de Baza". En T. Chapa y I. Izquierdo (eds.): La Dama de Baza. Un viaje femenino al más allá. Ministerio de Cultura. Madrid: 149-169.

Rísquez, C. 2015: "La arqueología ibérica y los estudios de género en Andalucía: avances y desafíos". Menga. Revista de Prehistoria de Andalucía 6: 61-91.

Rísquez, C. y García Luque, M. A. 2007: "Mujeres en el origen de la aristocracia ibera. Una lectura desde la muerte". Complutum 18: 263-270. https://revistas.ucm.es/index.php/CMPL/article/view/CMPL0707110263A

Romero, F. y Misiego J. C. 1995: "Desarrollo secuencial de la Edad del Hierro en el Alto Duero. El Castillejo (Fuensaúco, Soria)”. En F. Burillo (ed.): Poblamiento Celtibérico. III Simposio sobre los Celtíberos (Daroca 1991): 127-139. Zaragoza.
Ruiz Vélez, I. 2010: La necrópolis de la Primera Edad del Hierro de El Pradillo (Pinilla de Trasmonte, Burgos). Academia Burgalense de Historia y Bellas Artes, Institución Fernán González. Burgos.

Ruiz Zapatero, G. y Lorrio, A. 2000: “La 'belleza del guerrero': los equipos de aseo personal y el cuerpo en el mundo celtibérico". En E. Baquedano (ed.): Soria arqueológica: a José Luis Argente. Diputación Provincial de Soria. Soria: 279-310.

Sagardoy, T. y Chordá, M. 2010: "Ritos de comensalidad y delimitación del espacio funerario en la necrópolis de Herrería IV (Guadalajara)". En F. Burillo (ed.): Ritos y mitos. VI Simposio sobre los Celtiberos (Daroca 2008). Centro de Estudios Celtibéricos de Segeda. Mara: 331-340.

Sánchez Romero, M. (ed.) 2005a: Arqueología y Género. Editorial de la Universidad de Granada. Granada.

Sánchez Romero, M. 2005b: "Cultura material y actitudes de género: el utillaje lítico”. En M. Sánchez Romero (ed.): Arqueología y Género. Editorial de la Universidad de Granada. Granada: 219-243.

Sánchez Romero, M. 2006: "Maternidad y Prehistoria: prácticas de reproducción, relación y socialización”. En B. Soler Mayor (ed.): Las mujeres en la Prehistoria. Museu de Prehistòria de València. Valencia. http://mupreva.org/pub/306/es

Sánchez Romero, M. 2007: "Arqueología de las mujeres y de las relaciones de Género". Complutum 18: 163-165. https://revistas.ucm.es/ index.php/CMPL/article/view/CMPL0707110163A

Sánchez Romero, M. (ed.) 2010: "Infancia y cultura material en Arqueología”. Complutum 21 (2). Madrid. https://revistas.ucm.es/index.php/ CMPL/issue/view/CMPL101022

Sánchez Romero, M.; Alarcón, E. y Aranda, G. (eds.) 2015: Children, spaces and identity. Oxbow. Oxford.

Sánchez Romero, M. y Cid López, R. M. (eds.) 2018. Motherhood and infancies in the Mediterranean in Antiquity. Oxbow books. Oxford \& Philadelphia.

Sandars, H. 1913: The weapons of the Iberians. Oxford University Press. Oxford.

Sanz Mínguez, C. 1997: Los vacceos: cultura y ritos funerarios de un pueblo prerromano del valle medio del Duero. La necrópolis de Las Ruedas, Padilla de Duero (Valladolid). Memorias de Arqueología en Castilla y León 6, Junta de Castilla y León. Salamanca.

Sanz Mínguez, C. 2015: "Premature death in the Vaccei aristocracy at Pintia (Padilla de Duero/Peñafiel, Valladolid). Comparative study of the funerary rituals of two Little 'Princesses"'. En M. Sánchez Romero, E. Alarcón y G. Aranda (eds.): Children, spaces and identities. Oxbow Books. Oxford: 262-281.

Sanz Mínguez, C. y Coria, J. C. 2018: "La tumba 144 de la necrópolis de Las Ruedas". En C. Sanz Mínguez y J. F. Blanco (eds.): Novedades arqueológicas en cuatro ciudades vacceas: Dessobriga, Intercatia, Pintia y Cauca. Centro de Estudios Vacceos Federico Wattenberg. Valladolid: 129-153.

Sanz Mínguez, C. y Diezhandino, E. 2007: "Tumba 122: una posible mujer joven, de alta condición social". En C. Sanz Mínguez y F. Romero (eds.): En los extremos de la región vaccea. Caja España. León: 9194.

Sanz Mínguez, C. y Romero, F. 2010: "Mujeres, rango social y herencia en la necrópolis vaccea de Las Ruedas, Pintia (Padilla de Duero/ Peñafiel, Valladolid)". En F. Burillo (ed.): Ritos y mitos. VI Simposio sobre los Celtiberos (Daroca 2008). Centro de Estudios Celtibéricos de Segeda. Mara: 403-419.

Schüle, W. 1969: Die Meseta-Kulturen der Iberischen Halbinsel. Mediterrane und eurasische Elemente in Früheisenzeitlichen Kulturen Südwesteuropas. Walter de Gruyter. Berlín.

Sofaer, J. 2000: "Rings of life: the role of early metalwork in mediating the gendered life course". World Archaeology 31 (3): 389-406. https://doi.org/10.1080/00438240009696928

Sofaer, J. y Sørensen, M. L. S. 2013: "Death and Gender”. En S. Tarlow y L. Nilsson Stutz (eds.): The Oxford handbook of the archaeology of death and burial. Oxford University Press. Oxford.

Sørensen, M. L. S. 2000: Gender archaeology. Wiley. Oxford.

Taracena, B. 1932: Excavaciones de la provincia de Soria. Junta Superior de Excavaciones y Antigüedades 119. Madrid 